OPEN ACCESS

Edited by:

Jose Luis Contreras-Vidal,

University of Houston, USA

Reviewed by:

Brian H. Dalton,

University of British Columbia

Okanagan, Canada

Wei Peng Teo,

Deakin University, Australia

${ }^{*}$ Correspondence:

Chang S. Nam

csnam@ncsu.edu

Jason R. Franz

jifranz@email.unc.edu

Received: 15 December 2016 Accepted: 22 March 2017 Published: 10 April 2017

Citation:

Wittenberg E, Thompson J, Nam CS and Franz JR (2017) Neuroimaging of Human Balance Control: A Systematic

Review.

Front. Hum. Neurosci. 11:170. doi: 10.3389/fnhum.2017.00170

\section{Neuroimaging of Human Balance Control: A Systematic Review}

\author{
Ellen Wittenberg ${ }^{1}$, Jessica Thompson ${ }^{2}$, Chang S. Nam ${ }^{1 *}$ and Jason R. Franz ${ }^{2 *}$ \\ ${ }^{1}$ Edward P. Fitts Department of Industrial and Systems Engineering, North Carolina State University, Raleigh, NC, USA, ${ }^{2}$ Joint \\ Department of Biomedical Engineering, University of North Carolina at Chapel Hill and North Carolina State University, Chapel \\ Hill, NC, USA
}

This review examined 83 articles using neuroimaging modalities to investigate the neural correlates underlying static and dynamic human balance control, with aims to support future mobile neuroimaging research in the balance control domain. Furthermore, this review analyzed the mobility of the neuroimaging hardware and research paradigms as well as the analytical methodology to identify and remove movement artifact in the acquired brain signal. We found that the majority of static balance control tasks utilized mechanical perturbations to invoke feet-in-place responses (27 out of 38 studies), while cognitive dual-task conditions were commonly used to challenge balance in dynamic balance control tasks (20 out of 32 studies). While frequency analysis and event related potential characteristics supported enhanced brain activation during static balance control, that in dynamic balance control studies was supported by spatial and frequency analysis. Twenty-three of the 50 studies utilizing EEG utilized independent component analysis to remove movement artifacts from the acquired brain signals. Lastly, only eight studies used truly mobile neuroimaging hardware systems. This review provides evidence to support an increase in brain activation in balance control tasks, regardless of mechanical, cognitive, or sensory challenges. Furthermore, the current body of literature demonstrates the use of advanced signal processing methodologies to analyze brain activity during movement. However, the static nature of neuroimaging hardware and conventional balance control paradigms prevent full mobility and limit our knowledge of neural mechanisms underlying balance control.

\footnotetext{
Keywords: static and dynamic balance control, temporal and spatial dynamics of brain activation, mechanical perturbation, sensory degradation, susceptibility to cognitive dual tasks, movement artifacts
}

\section{INTRODUCTION}

Approximately $30 \%$ of adults aged 65 years or older experience one or more falls annually, a third of which result in a moderate to severe injury (Alexander et al., 1992). In addition to the high financial burden associated with these falls, there is also a loss of independence and increased risk of mortality (Brauer et al., 2000). With our aging population, the incidence of falls will likely continue to rise. Slips and falls are usually due extrinsic, environmental factors, including surface contamination, lighting, and shoe-type. However, intrinsic factors also contribute to falls, including age, pathologies, medications, attention, fatigue, and physical status (Gauchard et al., 2001). Loss of static balance control, such as can occur when standing on a moving bus, and loss of dynamic balance control, such as can occur when walking in a dark room, both contribute to slips and falls. 
Static and dynamic human balance control, and changes thereof due to intrinsic and extrinsic factors, have garnered considerable scientific and clinical attention. Walking balance control is especially dynamic, involving coordinated adjustments in posture (i.e., head and trunk stabilization) and foot placement from step to step (Bauby and Kuo, 2000; Kay and Warren, 2001; Donelan et al., 2004; Rankin et al., 2014). Particularly in unpredictable and challenging environmental conditions, these adjustments depend on the integration of reliable sensory feedback and the planning and execution of appropriate motor responses (O'Connor and Kuo, 2009; O'Connor et al., 2012; Francis et al., 2015; Franz et al., 2015, 2016; Goodworth et al., 2015). Accordingly, sensory and mechanical perturbations are increasingly used to study corrective motor responses in standing and walking and the onset and progression of balance deficits. Sensory perturbations may include those of visual (e.g., optical flow) (O'Connor and Kuo, 2009; O'Connor et al., 2012; Francis et al., 2015; Franz et al., 2015, 2016), somatosensory (e.g., tendon vibration) (Gurfinkel et al., 1976; Hay et al., 1996; Bove et al., 2003; Mullie and Duclos, 2014), or vestibular feedback (e.g., galvanic stimulation) (Day et al., 1993; Fitzpatrick et al., 1994; Bent et al., 2002; Dakin et al., 2007; Dalton et al., 2014), whereas mechanical perturbations most frequently incorporate support surface translations (Sinitksi et al., 2012; Aprigliano et al., 2016). Cortical activity and high-order cognitive processes are highly involved in the planning and execution of these motor responses. Indeed, dual tasks during standing and walking elicit cognitivemotor interference that compromise metrics of balance control (Dubost et al., 2006; Priest et al., 2008; Plummer et al., 2015).

Human balance control investigations have primarily focused on quantifying motor responses based on kinematic measurements such as movement variability and dynamic stability and/or kinetic measurements such as center of pressure and angular momentum (O'Connor and Kuo, 2009; McAndrew et al., 2011; Francis et al., 2015; Sheehan et al., 2015). These studies are rapidly accelerating our scientific understanding of human balance control, with exciting translational implications for the diagnosis and rehabilitation of people at risk of falls. However, this promising translational potential is currently limited by our relatively incomplete understanding of central mechanisms involved in human balance control and ultimately changes thereof due to aging or disease. Advancements in the use of neuroimaging, and in particular the development of advanced mobile measurements, are now providing previously inaccessible insight into brain connectivity during functional movement and balance tasks.

\section{REVIEW OBJECTIVES}

Evidence from neuroimaging studies reveals cortical involvement in standing and walking, with modalities having high spatial resolution, such as functional magnetic resonance imaging (fMRI), single-photon emission computed tomography (SPECT), and positron emission tomography (PET), leading to the identification of a supraspinal locomotor network (la Fougere et al., 2010; Zwergal et al., 2013). Within this supraspinal network, la Fougere et al. (2010) identified a direct locomotor pathway, used primarily during gait execution, and the indirect
TABLE 1 | Motor pathways in la Fougere et al. (2010).

\begin{tabular}{|c|c|c|}
\hline & Direct locomotor pathway & Indirect locomotor pathway \\
\hline $\begin{array}{l}\text { Brain } \\
\text { activation }\end{array}$ & $\begin{array}{l}\text { - Pre and post central gyrus } \\
\text { (BA } 3,4) \\
\text { - Lingual and fusiform gyrus } \\
\text { (BA 19,37) } \\
\text { - Parahippocampal gyrus } \\
\text { (BA } 36,27 \text { ) } \\
\text { - Cuneus and precuneus } \\
\text { (BA 18, 31) } \\
\text { - Insula and inferior frontal gyrus } \\
\text { (BA 13, 47) } \\
\text { - Cerebellum and brainstem } \\
\text { (vermis, paravermis, pontine } \\
\text { tegmentum) }\end{array}$ & $\begin{array}{l}\text { - } \text { Middle frontal gyrus (BA 6) } \\
\text { - Superior frontal gyrus (BA } \\
\text { 9,10) } \\
\text { - } \text { Parahippocampal gyrus } \\
\text { (BA 19, 36) } \\
\text { - Precuneus (BA 7, 31) } \\
\text { - } \text { Middle occipital gyrus (BA 18) } \\
\text { - } \text { Cingulate gyrus (BA 32, 24) } \\
\text { - } \text { Anterior insula (BA 13) } \\
\text { - Superior temporal gyrus } \\
\text { (BA 22) } \\
\text { - Supramarginal gyrus (BA 40) } \\
\text { - Putament, caudate nucleus, } \\
\text { cerebellum, and brainstem } \\
\text { (pontine tegmentum) }\end{array}$ \\
\hline $\begin{array}{l}\text { Brain } \\
\text { deactivation }\end{array}$ & $\begin{array}{l}\text { - Inferior temporal gyrus (BA 20) } \\
\text { - Inferior parietal lobe (BA 29) } \\
\text { - Frontal and medial frontal gyrus } \\
\quad \text { (BA 6) } \\
\text { - } \text { ACC (BA 32) }\end{array}$ & $\begin{array}{l}\text { - Superior temporal gyrus } \\
\text { (BA 22) }\end{array}$ \\
\hline
\end{tabular}

BA represents the Brodmann Area.

locomotor pathway, activated during gait planning (see Table 1). The main difference between the pathways involves activating the pre and post central gyri in the direct pathway in contrast to activating the dorsolateral prefrontal cortex (DLPFC) and basal ganglia in the indirect pathway. Furthermore, Zwergal et al. (2013) and others have observed activation of brain regions of the indirect locomotor pathway gait execution in populations with neurological disorders.

Neuroimaging studies utilizing functional near-infrared spectroscopy (fNIRS) have allowed for acquisition of brain activity during upright stance and with some degree of subject mobility. Using fNIRS, differential activation of the sensorimotor cortices, supplementary motor areas, and prefrontal cortex have been observed during gait initiation (i.e., standing to walking) and steady-state walking (Miyai et al., 2001; Suzuki et al., 2004; Mihara et al., 2012). Activation of the prefrontal cortex and supplementary motor areas have been correlated with variations in step-width and stride-time intervals (Kurz et al., 2012; Caliandro et al., 2015). Although the increased mobility of fNIRS has allowed for neuroimaging during real gait, research is still limited by poor temporal resolution. The use of electroencephalography (EEG) allows for higher temporal resolution and has potential for mobile applications (Jeon et al., 2011; Nam et al., 2011, 2012; Li and Nam, 2016). Advances in hardware systems have allowed for free movement in space, with wireless data transmission. Although the hardware is mobile, acquiring brain signals during movement introduces signal artifacts that compromise the integrity of underlying electrocortical activity (Gwin et al., 2010). Identifying and removing these artifacts has been challenging; however, recent advances in both hardware and signal analysis techniques show promise in developing fully mobile EEG neuroimaging systems (Gramann et al., 2014). 
Understanding the neural underpinnings of human balance control is an essential next step in addressing slip and fall risks in the general population. While spatial brain activation during steady-state walking has been reviewed by Hamacher et al. (2015), to our knowledge, there is no current review analyzing changes in brain activity due to static and dynamic balance control challenges, including spatial, temporal, and frequency analyses. Additionally, the impact of mobile neuroimaging hardware paired with non-restrictive balance control tasks has not yet been evaluated. Therefore, this study reviewed the current neuroimaging literature investigating the neural correlates of human balance control to address the following three research questions:

- Research Question (RQ) 1: What are the spatial and temporal dynamics of brain activity when mechanical perturbations, cognitive tasks, and modulation of sensory inputs challenge static balance control?

Evaluation of human balance control uses a variety of paradigms to challenge motor, cognitive, and sensory components of balance (de Oliveira et al., 2008). Animal models, lesion studies, and neuroimaging evidence support cortical involvement in maintaining upright stance due to external perturbations (Jacobs and Horak, 2007). However, the spatial and temporal characteristics of brain activity evoked in varying balance control paradigms has yet to be analyzed.

- Research Question (RQ) 2: What are the spatial and temporal dynamics of brain activity when mechanical challenges, cognitive tasks, and modulation of sensory inputs test dynamic balance control?

While brain activity during walking has been recently reviewed (Hamacher et al., 2015), there is no current analysis on the impact of balance challenges on dynamic balance control.

- Research Question (RQ) 3: What methods have been used to identify and remove movement artifact from brain signals acquired during balance control tasks?

Neuroimaging modalities are sensitive to head and body movement, which introduces movement artifact into the acquired brain signal. The characteristics of movement artifact are related to both the neuroimaging modality and the research paradigm, with minimal artifact when subjects are completely still. However, it is reasonable to expect sudden movements to maintain static balance control or rhythmic walking during dynamic balance control to introduce variable movement artifact. In order to identify neural mechanisms involved in balance control, movement artifact must be correctly identified and removed. Therefore, it is important to identify the artifact removal methods used in static and dynamic balance control studies.

\section{REVIEW METHOD}

\section{Search Strategy}

This systematic review utilized the Preferred Reporting Items for Systematic Reviews and Meta-Analyses (PRISMA; see Figure 1) approach (Liberati et al., 2009). The searches included detailed terms related to neuroimaging, static and dynamic balance control, and brain activity. The three search fields were connected with "AND" to ensure at least one term of each field could be found in the results. The terms in each of search field were linked with "OR."

\section{Search Terms}

Neuroimaging search terms included variations of the following: fMRI, EEG, fNIRS, MEG, PET, and SPECT. Balance control search terms included variations of the following: Standing, balance, posture, gait, stepping, walking, plantarflexion, dorsiflexion, locomotion, and postural control. Brain activity search terms included variations of the following: Cortical activity, subcortical activity, neural activity, executive function.

\section{Search Process}

The primary information sources included in this review are: (1) IEEExplore and (2) Compendex, both to provide an engineering perspective, (3) ACM Library, to provide a computing and signal processing perspective, (4) PubMed, to provide a clinical perspective, and (5) Web of Science, to provide a cross disciplinary perspective. The database search included search terms found in the article title, abstracts, and keywords. The results from each database were added to Mendeley and checked for any duplicate results.

\section{Inclusion and Exclusion Criteria}

Search inclusion and exclusion were based on the characteristics and goals of the balance control tasks and the use and application of neuroimaging modalities. Literature included in this review aimed to investigate human balance control. Studies were included if they incorporated balance challenges (e.g., perturbations, eyes closed, dual-task, etc.). Only articles in English were considered. We excluded literature from this review when either the balance control paradigm or the neuroimaging paradigm did not align with the goals of this study. Studies that evaluate the effects of a therapy or intervention, including drug or hormone trials, rehabilitation, training, robotic-assisted walking, or development (in children and adolescents) were excluded. Studies that did not include active subject movement, such as those using motor imagery, brain volume correlation, or passive walking paradigms were excluded. Passive walking paradigms are those where the experimenter or specially designed equipment assisted the subject in moving their legs (Dobkin et al., 2004). Additionally, studies that use isolated joint movement and coordinated body movement (arms and legs) were excluded. Lastly, studies that aimed to evaluate technological advancements with no concurrent evaluation of human subjects were excluded.

\section{Data Extraction}

After agreeing on studies to be included, the entirety of each article was examined, and studies were divided into two categories: (1) brain activity during static balance control tasks and (2) brain activity during dynamic balance control 


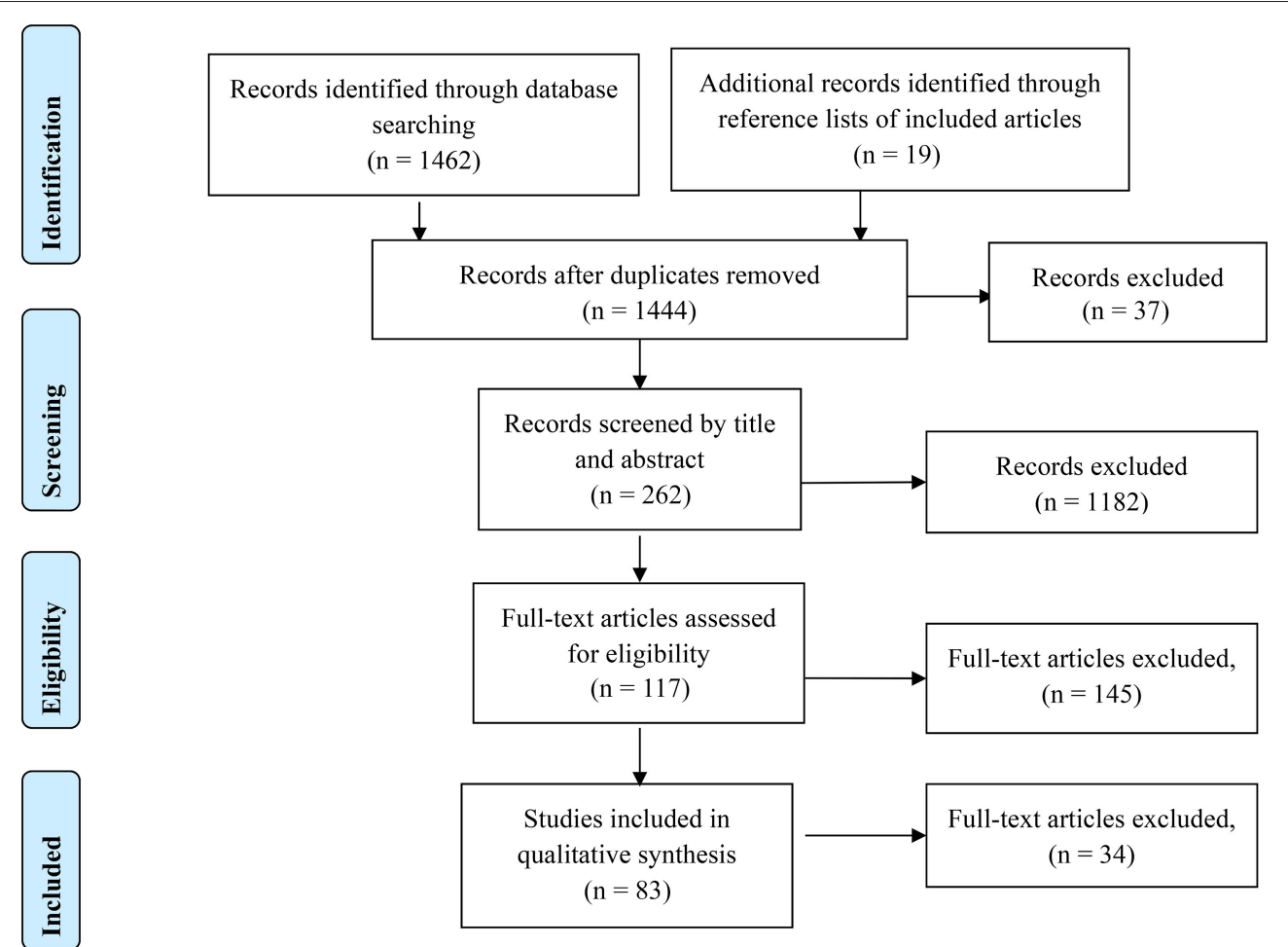

FIGURE 1 | PRISMA flow diagram of this review.

tasks. Studies in both groups that included methodologies for movement artifact identification and removal were pooled to address research question three. The subsequent data were then extracted from each article: Authors, year of publication, static or dynamic balance task, type of balance challenge (further categorized as sensory, mechanical or cognitive), treadmill or overground walking (for dynamic studies), subject characteristics, modality of brain imaging, and brain activity (including spatial, temporal, and/or frequency response). As well as extraction of pre-processing, spatial filtering, and artifact removal methods.

\section{RESULTS AND DISCUSSIONS}

\section{Study Selection and Characteristics}

Literature searches included relevant studies published on or before September 1,2016, and resulted in 1,462 results, with 1,444 studies remaining after duplicate removal. After initial screening of the abstract, 117 studies were evaluated for inclusion in the static balance control or dynamic balance control category. The full-text articles for each of the studies was reviewed, a total of 38 studies were eligible for inclusion in the static balance control group and 47 for the dynamic group, with two studies including both static and dynamic balance control tasks. All 83 studies included in the static and dynamic groups were evaluated for inclusion in addressing research question three regarding identification and removal of movement artifact. Figure 1 shows the PRISMA approach used in the present study.

\section{Studies Selected for RQ1}

This review covered 38 studies investigating neural correlates of static balance control. The balance challenge paradigms include mechanical perturbations, cognitive, dual-task paradigms and sensory degradation, or impairment, which can be found in Tables 2-4, respectively.

\section{Mechanical Challenges}

Twenty-seven studies used mechanical perturbations to elicit a balance control response, 15 of which focused on the evoked cortical potentials (See Table 2). The negative potential occurring around $100 \mathrm{~ms}$ following an event, such as mechanical perturbations, is termed the N100 potential. The N100 response over the fronto-central area has been observed in a wide range of balance tasks, and N100 amplitude increases in challenging balance control tasks, including unpredictable or surprise perturbations, and in balance challenges with low sensory inputs (Adkin et al., 2006, 2008; Mochizuki et al., 2008; Huang et al., 2014; Varghese et al., 2014, 2015). However, Mochizuki et al. (2009a) observed no difference in N100 latency and amplitude in sitting and standing instability conditions, suggesting that there may be more general processes that underlie stability, regardless of sensory, motor, or postural aspects of response.

$\mathrm{N} 100$ is also called the error related negativity potential (ERN), which is known to be evoked when an error is committed and to originate in the anterior cingulate cortex (ACC). Marlin et al. (2014) investigated if the perturbation evoked N100 and the ERN both originated in the ACC using a lean-and-release protocol 
TABLE 2 | Brain activity due to mechanical challenges to static balance control.

\begin{tabular}{|c|c|c|c|c|c|}
\hline Name, year & Balance challenge & Modality & Mobile & Spatial location & Activity \\
\hline Adkin et al., 2008 & Please refer to Table 3 & & & & \\
\hline Adkin et al., 2006 & $\begin{array}{l}\text { Single transient horizontal } \\
\text { perturbations to the trunk }\end{array}$ & EEG & No & $\mathrm{Cz}$ & N100 amplitude \\
\hline \multirow[t]{3}{*}{ Bulea et al., 2014} & Sit-to-stand transitions & EEG & Yes & $\begin{array}{l}\text { Frontal cortex, motor strip, } \\
\text { parietal cortex, and central }\end{array}$ & $\begin{array}{l}\text { Alpha and theta band power greater } \\
\text { at rest than pre-movement }\end{array}$ \\
\hline & & & & midline regions of interest & $\begin{array}{l}\text { Higher delta band power pre- and } \\
\text { post-movement vs. rest }\end{array}$ \\
\hline & & & & & $\begin{array}{l}\text { Classification of lower extremity } \\
\text { movement intent based on } \\
\text { pre-movement delta band signal }\end{array}$ \\
\hline Chang et al., 2016 & Please refer to Table 4 & & & & \\
\hline \multirow[t]{2}{*}{ Del Percio et al., 2009} & Unipedal vs. bipedal stance & EEG & No & $\begin{array}{l}\text { Lt and rt central, rt. and middle } \\
\text { parietal }\end{array}$ & Amplitude of alpha ERD \\
\hline & & & & Rt frontal, central, middle parietal & Amplitude of alpha ERD \\
\hline Huang et al., 2014 & Please refer to Table 3 & & & & \\
\hline \multirow[t]{2}{*}{ Hülsdünker et al., 2016} & $\begin{array}{l}\text { Unstable surface conditions via } \\
\text { platform unexpected perturbations }\end{array}$ & EEG & No & $\begin{array}{l}\text { Frontal, fronto-central, and } \\
\text { fronto-parietal }\end{array}$ & Alpha band power \\
\hline & & & & Midline & Theta band power \\
\hline \multirow[t]{2}{*}{ Hülsdünker et al., 2015} & $\begin{array}{l}\text { Bipedal vs. unipedal with various } \\
\text { levels of support surfaces }\end{array}$ & EEG & No & Frontal, Central, Parietal & Increased theta power \\
\hline & & & & Fronto-central, fronto-parietal & Theta power \\
\hline Jacobs et al., 2008 & $\begin{array}{l}\text { Unexpected vs. expected translation } \\
\text { of platform }\end{array}$ & EEG & No & $\mathrm{Cz}, \mathrm{Pz}, \mathrm{Fz}, \mathrm{F} 3, \mathrm{~F} 4$ & CNV \\
\hline \multirow[t]{2}{*}{ Marlin et al., 2014} & Stand lean and release task and & EEG & No & ACC & ERN Flanker task response \\
\hline & Flanker task & & & $\begin{array}{l}\text { Medial frontal gyrus and } \\
\text { supplementary motor area }\end{array}$ & N100 evoked by perturbations \\
\hline \multirow[t]{2}{*}{ Mierau et al., 2015} & Horizontal perturbations of platform & EEG & No & Localization in parietal cortex & P100 evoked by perturbations \\
\hline & & & & $\begin{array}{l}\text { Localization in midline } \\
\text { fronto-central cortex }\end{array}$ & N100 evoked by perturbations \\
\hline \multirow[t]{2}{*}{ Mihara et al., 2008} & Horizontal perturbations of platform & fNIRS & No & PFC, DLPFC & Activation after external perturbation \\
\hline & & & & $\begin{array}{l}\text { Rt. Posterior parietal cortex and } \\
\text { SMA }\end{array}$ & Increased activation \\
\hline \multirow[t]{2}{*}{ Mihara et al., 2012} & $\begin{array}{l}\text { Horizontal translations of platform in } \\
\text { older, hemiplegic stroke patients }\end{array}$ & fNIRS & No & PFC, premotor and parietal areas & $\begin{array}{l}\text { Increased activation due to } \\
\text { perturbation }\end{array}$ \\
\hline & & & & SMA and PFC & Activation \\
\hline Mochizuki et al., 2008 & $\begin{array}{l}\text { Unpredictable perturbations to the } \\
\text { support surface }\end{array}$ & EEG & No & $\mathrm{Cz}$ & N100 post-perturbation amplitude \\
\hline Mochizuki et al., 2009b & $\begin{array}{l}\text { Perturbations that were cued } \\
\text { externally or self-initiated }\end{array}$ & EEG & No & $\begin{array}{l}\mathrm{Cz}, \mathrm{FCz}, \mathrm{Fz}, \mathrm{CPz}, \mathrm{C} 1, \mathrm{C} 2, \mathrm{C} 3 \text {, } \\
\text { and } \mathrm{C} 4\end{array}$ & N100 post-perturbation amplitude \\
\hline \multirow[t]{2}{*}{ Mochizuki et al., 2009a } & \multirow{2}{*}{$\begin{array}{l}\text { Mechanical postural perturbations } \\
\text { during sitting and standing }\end{array}$} & \multirow[t]{2}{*}{ EEG } & \multirow[t]{2}{*}{ No } & $\mathrm{FCz}$ & Instability evoked N100 \\
\hline & & & & $\mathrm{CPz}$ & Amplitude of instability evoked P200 \\
\hline Ouchi et al., 1999 & Please refer to Table 4 & & & & \\
\hline Petrofsky and Khowailed, 2014 & Please refer to Table 4 & & & & \\
\hline Quant et al., 2005 & $\begin{array}{l}\text { Horizontal translations of platform } \\
\text { with varying deceleration }\end{array}$ & EEG & No & $\mathrm{Cz}$ & $\begin{array}{l}\text { N200 and P200 amplitude and } \\
\text { latency }\end{array}$ \\
\hline Slobounov et al., 2009 & $\begin{array}{l}\text { Single-legged, eyes-closed balance } \\
\text { task to study pre-falling, and } \\
\text { transition to instability }\end{array}$ & EEG & No & $\begin{array}{l}\text { ACC, precuneus, parietal lobe, } \\
\text { and occipital cortex }\end{array}$ & Theta, alpha, and gamma bands \\
\hline \multirow[t]{2}{*}{ Slobounov et al., 2008} & \multirow{2}{*}{$\begin{array}{l}\text { Voluntary postural sway in the AP and } \\
\text { ML directions }\end{array}$} & \multirow{2}{*}{ EEG } & \multirow[t]{2}{*}{ No } & Frontal, Fronto-central, parietal & Alpha, beta, gamma power \\
\hline & & & & & Amplitude of MRCP \\
\hline \multirow[t]{2}{*}{ Slobounov et al., 2005} & \multirow{2}{*}{$\begin{array}{l}\text { Oscillatory swaying motions in the } \\
\text { from the ankle }\end{array}$} & \multirow[t]{2}{*}{ EEG } & \multirow[t]{2}{*}{ No } & Frontal, Central & High gamma band \\
\hline & & & & Frontal, Central, Parietal & Presence of MRCP \\
\hline \multirow[t]{2}{*}{ Smith et al., 2012} & \multirow{2}{*}{$\begin{array}{l}\text { Backward surface translations in } \\
\text { older adults with or without PD }\end{array}$} & \multirow[t]{2}{*}{ EEG } & \multirow[t]{2}{*}{ No } & $\mathrm{Cz}$ & Beta band ERD \\
\hline & & & & $\mathrm{Cz}$ & Amplitude of CNV \\
\hline
\end{tabular}


TABLE 2 | Continued

\begin{tabular}{|c|c|c|c|c|c|}
\hline Name, year & Balance challenge & Modality & Mobile & Spatial location & Activity \\
\hline Smith et al., 2014 & $\begin{array}{l}\text { Mechanical perturbations while cued } \\
\text { to perform maximal postural response } \\
\text { in older, PD patients }\end{array}$ & EEG & No & $\begin{array}{l}\mathrm{Cp} 1, \mathrm{Cz} \\
\mathrm{Cz}\end{array}$ & $\begin{array}{l}\text { Alpha, Beta ERD } \\
\text { Amplitude CNV }\end{array}$ \\
\hline Tse et al., 2013 & Please refer to Table 4 & & & & \\
\hline Varghese et al., 2015 & Please refer to Table 4 & & & & \\
\hline Varghese et al., 2014 & Lean and release cable system & EEG & No & $\mathrm{FCz}$ & Perturbation evoked N100 amplitude \\
\hline
\end{tabular}

to invoke a feet-in-place balance response [similar to those in: Adkin et al. (2006) and Mochizuki et al. (2008)] and used dipole analysis to locate the N100 response. The ERN was localized to the ACC, as expected. However, the perturbation related N100 was localized to the medial frontal gyrus and supplementary motor area. These results indicate that perturbation evoked N100 is related to motor processes rather than a general error event.

Although there has been research in the early cortical response following perturbations, the role of later potentials is still unclear. In the auditory domain, for example, the event related potential (ERP) component around $200 \mathrm{~ms}$ post-stimulus (P200), represents a shift in attention toward the initial audio cue. Quant et al. (2005) used horizontal platform translations with quick or delayed deceleration to determine if P200 in the balance domain was related to a shift in attention or indicated sensory or motor processes. There was no difference in N200 and P200 amplitude or latency in immediate vs. delayed decelerations, suggesting that the motor reactions needed to maintain stability and later cortical responses are likely independent (Quant et al., 2005). Another event related potential is the contingent negative variation (CNV), a slow potential related to anticipatory attention, preparation, and motivation (Nagai et al., 2004). The $\mathrm{CNV}$ has been observed in response to unexpected surface perturbations in the midline and frontal areas (Jacobs et al., 2008) and to perturbations with an unexpected magnitude at $\mathrm{Cz}$ (Smith et al., 2012). Subjects in these studies are preparing for an unexpected surface perturbation, which explains the CNV response. However, Smith et al. (2014) provided amplitude cuing of the upcoming response in Parkinson's Disease patients and did not observe a CNV response. Given that subjects successfully demonstrated balance control, these results indicate that another type of cortical response is involved in cued responses.

Thirteen EEG studies performed frequency analysis. As task difficulty increased (for example, decreased surface support due to standing on foam), alpha power in healthy controls decreased, indicating increased cortical activation (Petrofsky and Khowailed, 2014; Hülsdünker et al., 2016). Slobounov et al. (2008) observed a larger decrease in alpha power in central electrodes prior to sway in the medio-lateral direction compared to an anterior-posterior sway. While performance studies have found anterior-posterior sway magnitude and torque is larger than medio-lateral sway, these results suggest that cortical activity may be sway-direction dependent, with medio-lateral instability requiring more cortical control in self-initiated postural movements. Lastly, Slobounov et al. (2009) saw a drop in alpha power in occipital region prior to a fall. However, when subjected to the challenging balance conditions, trans-tibial amputees exhibited an increase in alpha power (Petrofsky and Khowailed, 2014). Chang et al. (2016) challenged balance control of older adults in high and low fall risk groups by subjecting them to anterior-posterior motion via a Steward Platform. Two conditions were tested with and without a virtual-reality based scenery synchronized with the motion platform. Beta band power increased in the virtual-reality condition in the frontal and occipital regions for both groups. Petrofsky and Khowailed (2014) also observed an increase in beta power as balance challenges increased in central and parietal areas of both controls and amputee patients. Tse et al. (2013) also found increase in beta power with increase in balance challenge task (base of support or surface compliance) in the parietal and central areas. Smith et al. (2012) observed an increased in beta band event related desynchronization (ERD) at $\mathrm{Cz}$ for predictability predictable, small magnitude perturbations. However, in a similar paradigm with and without amplitude cuing, Smith et al. (2014) did not observe a significant difference in beta power between the two conditions. In comparing the demands of balance during mediolateral and anterior-posterior sway, Slobounov et al. (2008) found that beta power in the central region dropped significantly more prior a self-initiated ML sway.

Recent studies have also investigated theta band increases in challenging balance tasks in frontal, central, and parietal areas (Hülsdünker et al., 2015, 2016; Chang et al., 2016). Hülsdünker et al. (2015) found that theta power over the fronto-central and central-parietal areas correlated with balance performance. Slobounov et al. (2009) found a midline theta burst during the shift from the stable stage to transition-to-instability stage which was localized to the ACC. This burst was followed by the reduction of theta power just preceding an actual fall. Lastly, gamma activation in various areas of the brain have been shown to increase with increased balance challenge (Tse et al., 2013; Chang et al., 2016). More specifically, gamma activity increased right before the initiation of a balance reaction in the frontal and central areas (Slobounov et al., 2005, 2008). These findings indicate that theta increases correspond with the timing of balance control reactions. Bulea et al. (2014) also found that the low frequencies of the EEG signal contain information regarding lower extremity movement and balance control. Utilizing the delta band frequencies from EEG signal acquired while subjects 
transitioned from sitting to standing posture, they were able to classify movement intent (i.e., if the subject was going to stand-up, sit-down, or remain at rest).

While neuroimaging analysis following EEG signal acquisition has high temporal resolution, it lacks spatial resolution. Therefore, PET and fNIRS have been used to investigate the spatial characteristics of a balance response. Ouchi et al. (1999) observed the hemodynamic response following bipedal or unipedal stance with eyes open or closed using PET, finding an increased activation of the cerebellar anterior vermis and posterior lobe lateral cortex during unipedal stance and increased activation of the cerebellar anterior lobe and right visual cortex during bipedal stance. The visual cortex and vermis were activated during standing with feet together with eyes on a target as well (Ouchi et al., 1999). These findings provide spatial insights into neural correlates of balance control, mainly that the cerebellar vermis and visual cortex may be involved in maintaining and regulating standing posture. Studies using fNIRS also reveal cortical involvement in balance control. Mihara et al. (2008) observed an activation of the prefrontal cortex (PFC) and dorsolateral prefrontal cortex (DLPFC) after anterior-posterior and medio-lateral horizontal perturbations accompanied by increased activation of the right posterior parietal cortex and supplementary motor area in conditions with auditory warning signals. Similarly, Mihara et al. (2012) observed activation of prefrontal cortex, premotor, and parietal areas following anterior-posterior and medio-lateral horizontal perturbations in older, hemiplegic stroke patients. These findings point to involvement of the prefrontal, premotor, supplementary motor, and parietal cortex in standing balance control.

\section{Cognitive Challenges}

Seven studies required subjects to maintain balance while performing a cognitive dual-task paradigm (See Table 3). Dualtask paradigms necessitate allocation of attentional resources to perform both the cognitive and balance tasks, and performance outcomes have correlated with the integrity of balance control.

A decrease in N100 amplitude was observed in visual working memory task and visuo-motor track task conditions (Quant et al., 2004; Little and Woollacott, 2015). Similarly, Huang et al. (2014) provided subjects with visual feedback to facilitate maintaining balance on a tilt platform, resulting in decreased N100 amplitude over the motor cortex and sensorimotor areas. These studies found a decrease in N100 in the dual-task conditions, indicating their efficacy to split attentional resources between balance and cognitive tasks. In contrast, Adkin et al. (2008) evoked an emotional response (fear; anxiety) by placing subjects at a prescribed height off the ground. An N100 response was observed prior to an unpredictable perturbation, and N100 amplitude increased with increasing height. Mirelman et al. (2014) had subjects stand still and perform serial seven subtractions, a common cognitive loading task, resulting in increased activation in the left and right frontal lobe compared to single-task standing. Fujita et al. (2016) also observed increased brain activity in a cognitive DT paradigm using fNIRS. High and low memory span groups performed one or two leg standing with a Stroop task. Increased right dorsolateral prefrontal cortex activation was observed in the high span group in both one and two leg standing dual-task conditions, compared to the low span group. Also, performance in both groups decreased during one leg, dual-task standing. Lastly, Lau et al. (2014) compared effective connectivity during standing or walking with or without a visual oddball discrimination response task. They found that connectivity was weaker during standing when performing a cognitive task in the prefrontal cortex, posterior parietal cortex, and ACC. However, effective connectivity was stronger in the standing conditions compared to the walking condition regardless of cognitive task. These findings suggest that more cognitive resources may be required to maintain standing posture, as compared to walking (Lau et al., 2014).

\section{Sensory Challenges}

Experimentally manipulating sensory inputs (vestibular, visual, or proprioceptive) is another method to challenge balance control. Eleven studies used a form of sensory removal or augmentation, including eyes closed conditions and the use of virtual reality (See Table 4). For example, subjects stood with eyes closed and feet together or in tandem (i.e., heel-to-toe), which is more challenging, and N100 was evoked prior to the need for a balance reaction. The N100 amplitude increased with increasing postural challenge (Varghese et al., 2015).

Chang et al. (2016) utilized frequency analysis and observed a modulation of alpha, beta, gamma, and theta band power in response to balance challenge in a virtual reality environment, particularly an increase in alpha power in occipital lobe in the virtual reality condition in both groups. Del Percio et al. (2007) also observed and larger amplitude of alpha band ERD in athletes in a closed-eye one and two leg balance task, compared to non-athletes. In contrast, Pirini et al. (2011) observed a decrease in alpha power during eyes-open task in the right inferior parietal area, which is in line with the increased attention required to perform a balance under degraded conditions. Petrofsky and Khowailed (2014) also observed an increase in activation with increased balance challenge, finding an overall signal power increased with a decrease in the amount of qality of sensory feedback. Likewise, Tse et al. (2013) observed an increase in beta and sigma bands in parietal and central areas with a more difficult balance challenge.

Using fNIRS, Karim et al. (2013) found increased activation of the bilateral temporal-parietal areas when both vision and perceptual information were degraded (eyes closed, swaying floors). Mitsutake et al. (2015) aimed to induce instability by requiring subjects to rotate their heads while on a rotating platform. Using fNIRS, they found that activation at the central, frontal and temporal cites were not significantly different during high or low speed rotations despite these differences in stability. This may indicate different types of instability may differentially affect cortical or spinal control mechanisms.

\section{Studies Selected for RQ2}

Initial searches yielded 47 studies investigating brain activity during both steady-state walking and dynamic balance control tasks. Given that brain activity during steady-state walking has 
TABLE 3 | Brain activity due to cognitive challenges to static balance control.

\begin{tabular}{|c|c|c|c|c|c|}
\hline Name, year & Balance challenge & Modality & Mobile & Spatial location & Activity \\
\hline Adkin et al., 2008 & Perturbation under postural threat & EEG & No & $\mathrm{Cz}$ & $\begin{array}{l}\text { Perturbation evoked N100 } \\
\text { amplitude }\end{array}$ \\
\hline Fujita et al., 2016 & $\begin{array}{l}\text { Stroop task during bipedal vs. } \\
\text { unipedal standing }\end{array}$ & fNIRS & No & Rt. DLPFC & Increased activation \\
\hline \multirow[t]{3}{*}{ Huang et al., 2014} & Tilt platform using visual feedback & EEG & No & $\begin{array}{l}\text { Bi. lat. fronto-central and contralateral } \\
\text { sensorimotor areas }\end{array}$ & $\begin{array}{l}\text { Latency and amplitude of } \mathrm{N} 100 \\
\text { for postural control }\end{array}$ \\
\hline & & & & $\begin{array}{l}\text { Bi. lat. fronto-central and ipsilateral } \\
\text { temporal areas }\end{array}$ & $\begin{array}{l}\text { Latency and amplitude of P200 } \\
\text { for postural control }\end{array}$ \\
\hline & & & & Lt. frontal-central area & MRP for postural control \\
\hline \multirow[t]{2}{*}{ Lau et al., 2014} & \multirow{2}{*}{$\begin{array}{l}\text { Visual oddball response task while } \\
\text { standing or walking }\end{array}$} & \multirow[t]{2}{*}{ EEG } & \multirow[t]{2}{*}{ No } & Sensorimotor cortex & Effective connectivity \\
\hline & & & & PFC, posterior parietal cortex, ACC & Effective connectivity \\
\hline $\begin{array}{l}\text { Little and Woollacott, } \\
2015\end{array}$ & $\begin{array}{l}\text { Visual WM capacity during surface } \\
\text { perturbations and walking }\end{array}$ & EEG & No & Lt. pre-motor and rt. sensory areas & Amplitude of N100 ERP \\
\hline Mirelman et al., 2014 & $\begin{array}{l}\text { Walking while counting forward, } \\
\text { walking with serial } 7 \text { 's and serial } 7 \text { 's in } \\
\text { standing }\end{array}$ & fNIRS & No & Fp1 and Fp2 & $\begin{array}{l}\text { Increased activation with } \\
\text { increased task difficulty }\end{array}$ \\
\hline Quant et al., 2004 & $\begin{array}{l}\text { Horizontal translations platform with } \\
\text { or without a visuomotor track task }\end{array}$ & EEG & No & $\mathrm{Cz}$ & $\begin{array}{l}\text { Amplitude of perturbation } \\
\text { evoked N100 }\end{array}$ \\
\hline
\end{tabular}

It., left; rt., right; bi. lat., bilateral; PFC, prefrontal cortex; ACC, anterior cingulate cortex; MRP, movement related potential.

TABLE 4 | Brain activity due to sensory challenges to static balance control.

\begin{tabular}{|c|c|c|c|c|c|}
\hline Name, year & Balance challenge & Modality & Mobile & Spatial location & Activity \\
\hline Chang et al., 2016 & $\begin{array}{l}\text { Platform perturbations with and without synced } \\
\text { VR in older adults }\end{array}$ & EEG & No & $\begin{array}{l}\text { Parietal-occipital region } \\
\text { Frontal-central region } \\
\text { Occipital lobe }\end{array}$ & $\begin{array}{l}\text { Gamma, beta bands } \\
\text { Theta band } \\
\text { Alpha band }\end{array}$ \\
\hline Del Percio et al., 2007 & Standing with eyes open or closed & EEG & No & Rt. ventral CP area & Alpha band ERD amplitude \\
\hline Karim et al., 2013 & $\begin{array}{l}\text { Fixed floor, eyes open light/dark, } \\
\text { sway-referenced floor, eyes open light/dark }\end{array}$ & fNIRS & No & $\begin{array}{l}\text { Bi. Lat. temporal-parietal } \\
\text { areas }\end{array}$ & Activation \\
\hline Mitsutake et al., 2015 & Head rotations on a rotating platform & fNIRS & No & $\mathrm{Cz}, \mathrm{T} 3, \mathrm{~T} 4, \mathrm{~F} 3, \mathrm{~F} 4$ & Activation \\
\hline Ouchi et al., 1999 & $\begin{array}{l}\text { Bipedal or unipedal stance; eyes open or } \\
\text { closed }\end{array}$ & PET & No & $\begin{array}{l}\text { Cerebellar anterior vermis, } \\
\text { visual cortex, PFC }\end{array}$ & Activation \\
\hline $\begin{array}{l}\text { Petrofsky and Khowailed, } \\
2014\end{array}$ & $\begin{array}{l}\text { Eyes open/closed, surface compliance, base of } \\
\text { support in amputees vs. controls }\end{array}$ & EEG & No & $\begin{array}{l}\mathrm{Fz}, \mathrm{F} 3, \mathrm{~F} 4, \mathrm{Cz}, \mathrm{C} 3, \mathrm{C} 4 \\
\mathrm{POz}, \mathrm{P} 3 \text {, and P4 }\end{array}$ & $\begin{array}{l}\text { Alpha, beta, and sigma } \\
\text { band power }\end{array}$ \\
\hline Pirini et al., 2011 & $\begin{array}{l}\text { Auditory feedback in eyes open vs. eyes closed } \\
\text { scenarios }\end{array}$ & EEG & No & $\begin{array}{l}\text { Rt inferior parietal } \\
\text { Lt temporo-parietal, Lt } \\
\text { temporo-occipital }\end{array}$ & $\begin{array}{l}\text { Alpha power } \\
\text { Gamma power }\end{array}$ \\
\hline Slobounov et al., 2015 & $\begin{array}{l}\text { Maintain balance in heel-to-toe stance while } \\
\text { subjected to 2D or 3D VR moving room }\end{array}$ & EEG & No & Frontal midline & Theta power \\
\hline Slobounov et al., 2013 & Optical flow with various degrees of uncertainty & EEG & No & Frontal-central areas & Theta power \\
\hline Tse et al., 2013 & $\begin{array}{l}\text { Eyes open/ closed; Firm/foam surface; Regular } \\
\text { stance/heel-toe position }\end{array}$ & EEG & No & Parietal and central areas & $\begin{array}{l}\text { Beta and Sigma band } \\
\text { power }\end{array}$ \\
\hline Varghese et al., 2015 & $\begin{array}{l}\text { Standing with eyes closed and feet together or } \\
\text { feet heel-to-toe position }\end{array}$ & EEG & No & $\mathrm{Cz}$ & $\begin{array}{l}\text { Amplitude of } \mathrm{N} 100 \text { evoked } \\
\text { prior to balance reaction }\end{array}$ \\
\hline
\end{tabular}

TM, treadmill; OG, overground; VR, virtual reality; It., left; rt., right; bi. lat., bilateral; ERD, event related desynchronization.

been thoroughly reviewed by Hamacher et al. (2015), this review only includes the remaining 32 studies investigating brain activity under challenges to dynamic balance control. The balance challenge paradigms include mechanical perturbations, the use of cognitive dual-tasks, and the experimental manipulation of sensory inputs. Results can be found in Tables 5-7, respectively.

\section{Mechanical Challenges}

A total of 15 studies investigated the brain activity response due to mechanical challenges to dynamic balance control (See Table 5). Five studies utilized fNIRS paradigms to investigate frontal and prefrontal cortex activity. Clark et al. (2014b) used multiple mechanical challenges to increase the complexity of walking, including negotiating obstacles, carrying a tray and 
TABLE 5 | Brain activity due to mechanical challenges to dynamic balance control.

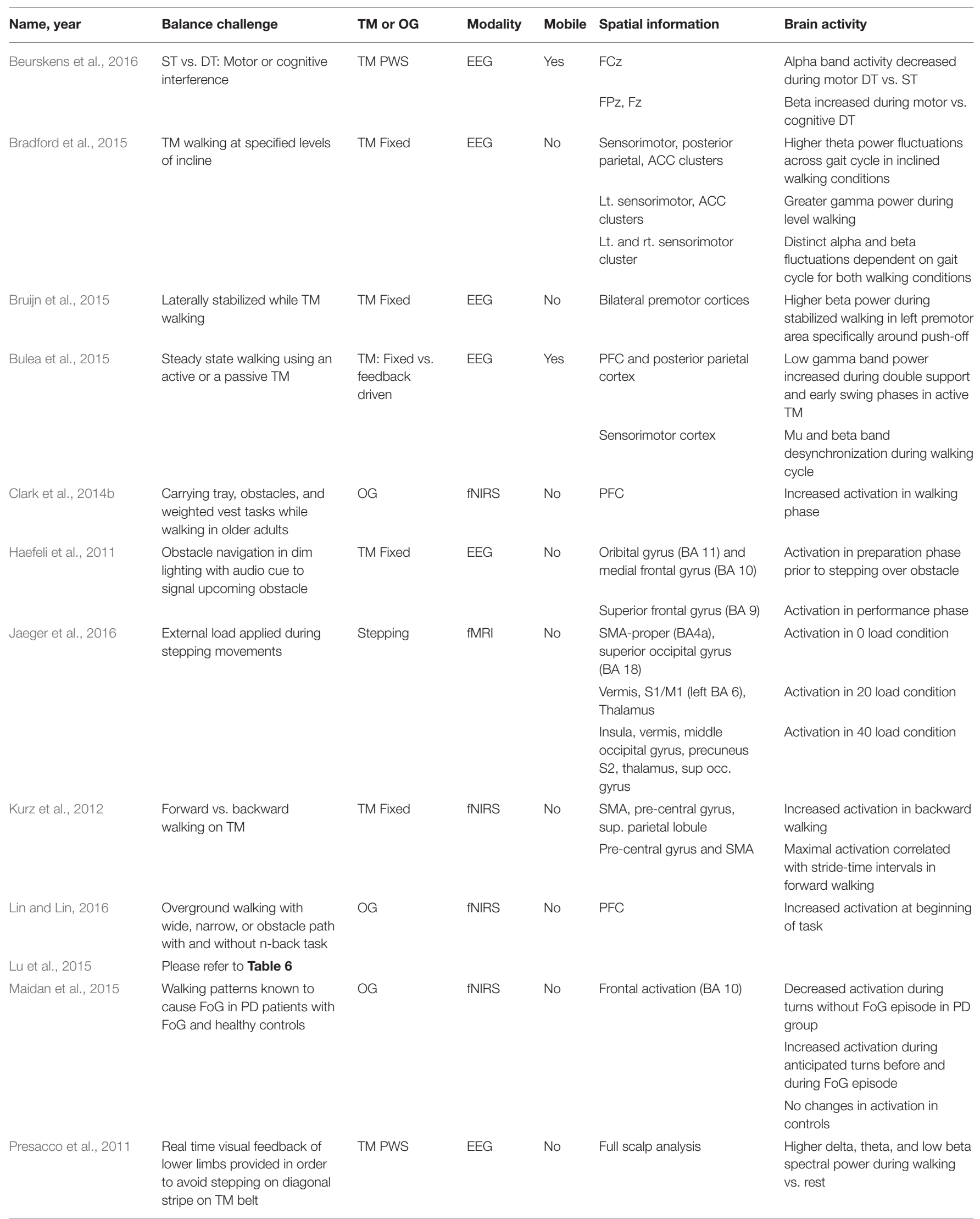


TABLE 5 | Continued

\begin{tabular}{|c|c|c|c|c|c|c|}
\hline Name, year & Balance challenge & TM or OG & Modality & Mobile & Spatial information & Brain activity \\
\hline & & & & & $\begin{array}{l}\text { Prefrontal, central, } \\
\text { posterior-occipital, right, } \\
\text { and left hemisphere regions } \\
\text { of interest }\end{array}$ & $\begin{array}{l}\text { Fluctuations in amplitude in EEG } \\
\text { signals in low delta frequency } \\
\text { band can predict gait kinematics }\end{array}$ \\
\hline Presacco et al., 2012 & $\begin{array}{l}\text { Real time visual feedback of } \\
\text { lower limbs provided in order } \\
\text { to avoid stepping on diagonal } \\
\text { stripe on TM belt }\end{array}$ & TM PWS & EEG & No & $\begin{array}{l}\text { Pre-frontal, motor, parietal, } \\
\text { and occipital areas }\end{array}$ & $\begin{array}{l}\text { Standardized voltage level } \\
\text { fluctuations over time can predict } \\
\text { gait kinematics }\end{array}$ \\
\hline \multirow[t]{3}{*}{ Sipp et al., 2013} & $\begin{array}{l}\text { Heel-to-toe walking on a } \\
\text { TM-mounted balance beam }\end{array}$ & TM Fixed & EEG & No & $\begin{array}{l}\text { ACC, anterior parietal, } \\
\text { superior DLPFC, medial } \\
\text { sensorimotor cortex }\end{array}$ & $\begin{array}{l}\text { Larger mean theta power during } \\
\text { walking on balance beam vs. TM }\end{array}$ \\
\hline & & & & & $\begin{array}{l}\text { Lt. and rt. sensorimotor } \\
\text { cortex clusters }\end{array}$ & $\begin{array}{l}\text { Lower beta power during } \\
\text { walking on balance beam vs. TM }\end{array}$ \\
\hline & & & & & Lt. sensorimotor cortex & $\begin{array}{l}\text { Visible indication on spectrogram } \\
\text { when falling off beam }\end{array}$ \\
\hline \multirow[t]{3}{*}{ Varghese et al., 2016} & $\begin{array}{l}\text { APA for lateral weight shift or } \\
\text { stepping task with/without } \\
\text { preloading weight to the } \\
\text { stance leg }\end{array}$ & Stepping & EEG & No & $\begin{array}{l}\text { Mid fronto-central } \\
\text { electrodes }\end{array}$ & $\begin{array}{l}\text { Increase in amplitude of } \\
\text { movement related potentials } \\
\text { prior to initiation of postural } \\
\text { adjustment }\end{array}$ \\
\hline & & & & & & $\begin{array}{l}\text { Movement related potentials } \\
\text { associated with APA onset }\end{array}$ \\
\hline & & & & & & $\begin{array}{l}\text { ERD of mu and beta bands } \\
\text { associated with APA onset }\end{array}$ \\
\hline
\end{tabular}

TM, treadmill; OG, overground; PW, preferred walking speed; ST, single task; DT, dual task; APA, anticipatory postural adjustment; PD, Parkinson's Disease; FoG, freezing of gait; BA, Brodmann Area; It., left; rt., right; bi. lat., bilateral; PFC, prefrontal cortex; DLPFC, dorsolateral prefrontal cortex; ACC, anterior cingulate cortex; SMA, supplementary motor area; ERD, event related desynchronization.

walking with a weighted vest. Prefrontal cortex (PFC) activation increased prior to walking for all three challenges compared to steady state walking. Increased prefrontal cortex activation during the weighted vest and obstacle conditions was also observed. Lu et al. (2015) also had subjects carry an object while walking and observed an increase in prefrontal cortex activation during task initiation, an increase in supplementary motor area (SMA) and premotor cortex (PMC) activation during the task. In addition, an increase in premotor cortex and supplementary motor area activation correlated with decreased gait performance.

Using a truly mobile fNIRS hardware system contained in a backpack, subjects walked over narrow, wide, or obstacle path conditions (Lin and Lin, 2016). At the beginning of each trial, regardless of path condition, average prefrontal cortex activation was higher and had larger variability compared to the end of the trial. Lastly, in healthy controls and Parkinson's Disease patients with freezing of gait (FoG), Maidan et al. (2015) monitored frontal activation during walking patterns known to cause FoG episodes. In the Parkinson's patients, frontal activation was decreased during turns without FoG episodes but increased during anticipated turns before and during FoG episodes. In the healthy controls, there was no change in frontal activation during turns.

Eight studies utilized EEG paradigms to investigate mechanical challenges to dynamic balance control. Bradford et al. (2015) required subjects to walk on a treadmill at specified inclines and observed theta power fluctuations that increased at steeper inclines in the ACC, sensorimotor, and posterior parietal clusters. Similarly, Sipp et al. (2013) found that heel-to-toe walking on a TM-mounted balance beam caused an increase in theta power in the ACC, anterior parietal, superior dorsolateral prefrontal cortex, and medial sensorimotor cortex. Lastly, Presacco et al. (2011) observed higher grand average spectral power within the delta and theta bands while subjects performed precision walking to avoid an obstacle on the treadmill belt. Beurskens et al. (2016) observed an alpha band decrease at the FCz electrode during dual-task condition requiring subject to walk and perform a motor interference task (preventing sticks in both hands from touching) compared to steady state walking. They also observed an increase in beta power in this motor-interference DT condition in the FPz and Fz electrodes. Bruijn et al. (2015) also observed an increase in beta power during stabilized walking in the premotor area specifically around push-off. However, Sipp et al. (2013) found a lower beta band power during balance beam walking in the sensorimotor cortex clusters. In general, Sipp et al. (2013) found an increase normalized time-frequency spectrogram in the ACC, parietal cortex, and dorsolateral prefrontal cortex time locked to gait cycle during the loss of balance and visible electrocortical indications on the spectrogram for the left sensorimotor cortex prior to a fall. Haefeli et al. (2011) had subjects avoid obstacles while walking under reduced vision conditions, with an audio cue to alert the subject of the obstacle, observing an increase in prefrontal cortex activity compared to steady-state walking. More specifically, prior to stepping over the obstacle, the EEG 
TABLE 6 | Brain activity due to cognitive challenges to dynamic balance control.

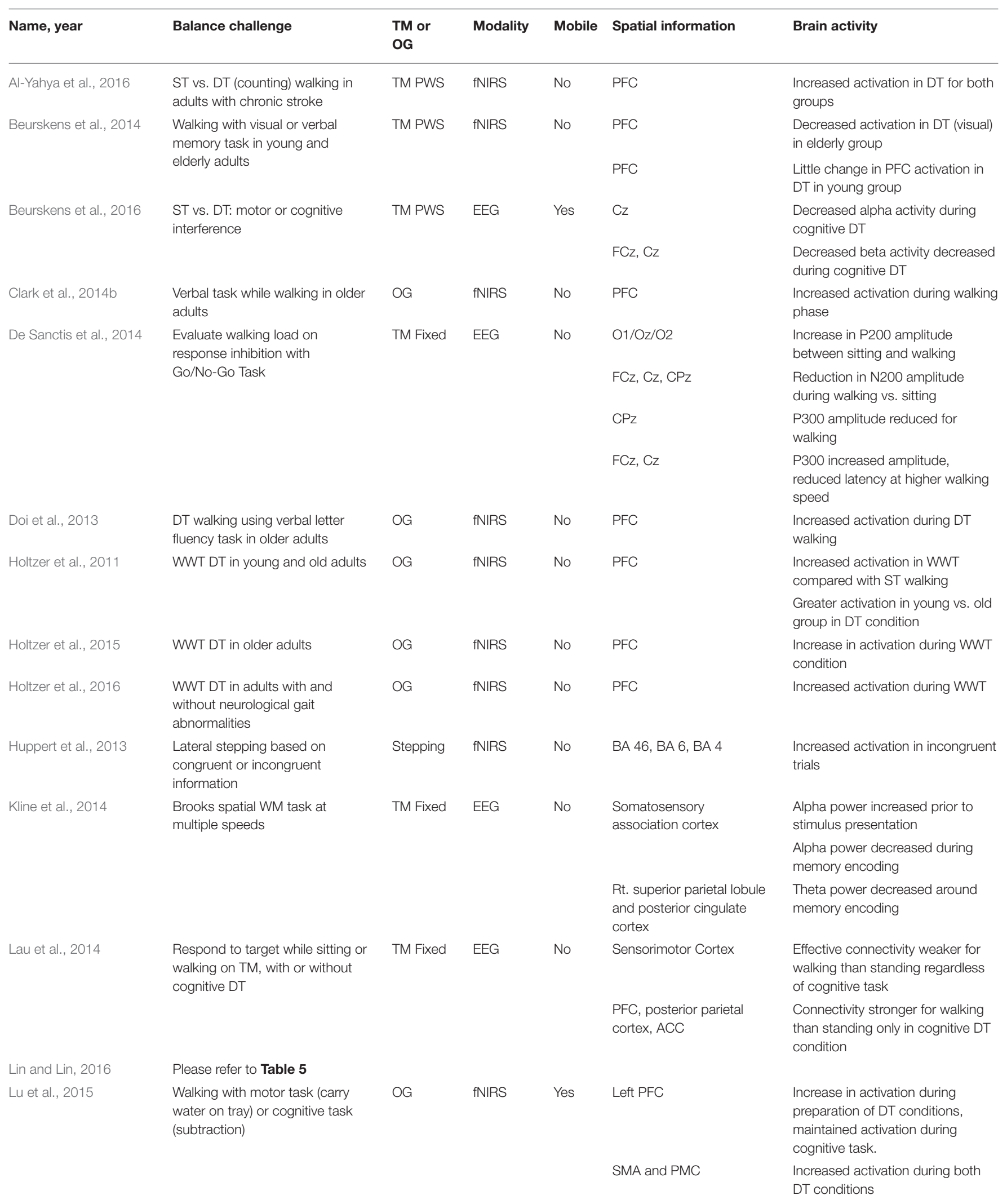


TABLE 6 | Continued

\begin{tabular}{|c|c|c|c|c|c|c|}
\hline Name, year & Balance challenge & $\begin{array}{l}\text { TM or } \\
\text { OG }\end{array}$ & Modality & Mobile & Spatial information & Brain activity \\
\hline & & & & & PMC and SMA & $\begin{array}{l}\text { Increased activation correlated } \\
\text { with declines in gait performance }\end{array}$ \\
\hline \multirow[t]{3}{*}{ Malcolm et al., 2015} & \multirow{3}{*}{$\begin{array}{l}\text { Go/No-go task while sitting or } \\
\text { walking in young and old healthy } \\
\text { adults }\end{array}$} & \multirow[t]{3}{*}{ TM Fixed } & \multirow[t]{3}{*}{ EEG } & \multirow[t]{3}{*}{ No } & \multirow[t]{3}{*}{$\mathrm{Cz}, \mathrm{FCz}$, and $\mathrm{CPz}$} & $\begin{array}{l}\text { Decreased N200 amplitude for DT } \\
\text { condition in young adults }\end{array}$ \\
\hline & & & & & & $\begin{array}{l}\text { Reduced N200 latency for DT } \\
\text { condition compared in young } \\
\text { adults }\end{array}$ \\
\hline & & & & & & $\begin{array}{l}\text { Reduced P300 latency compared } \\
\text { to sitting condition }\end{array}$ \\
\hline Mirelman et al., 2014 & $\begin{array}{l}\text { Walking while counting forward, } \\
\text { walking with serial } 7 \text { 's }\end{array}$ & OG & fNIRS & No & Fp1 and Fp2 & $\begin{array}{l}\text { Increased activation with increased } \\
\text { task difficulty. }\end{array}$ \\
\hline Osofundiya et al., 2016 & $\begin{array}{l}\text { DT walking (WWT), simple } \\
\text { walking, and precision walking in } \\
\text { older adults (obese and } \\
\text { controls)-Holtzer } 2011 \text {, } \\
\text { Verghese } 2002\end{array}$ & OG & fNIRS & No & PFC & $\begin{array}{l}\text { Oxygenation levels were higher in } \\
\text { complex ambulatory tasks } \\
\text { Higher oxygenation levels in obese } \\
\text { group (performance metrics were } \\
\text { the same) }\end{array}$ \\
\hline \multirow[t]{2}{*}{ Shine et al., 2013a } & \multirow[t]{2}{*}{$\begin{array}{l}\text { Stop-signal task in a VR } \\
\text { environment to navigate a } \\
\text { corridor using foot pedals. } \\
\text { Cognitive load modulated by } \\
\text { Stroop task. Older adults with } \\
\text { PD, with or without FoG }\end{array}$} & \multirow[t]{2}{*}{ Stepping } & \multirow[t]{2}{*}{ fMRI } & \multirow[t]{2}{*}{ No } & $\begin{array}{l}\text { Bi. lat. posterior parietal } \\
\text { cortices, midline pre-SMA, } \\
\text { bi. lat. anterior insula, } \\
\text { medial temporal lobes, } \\
\text { extra-striate visual cortex }\end{array}$ & $\begin{array}{l}\text { Activation in both groups when } \\
\text { walking with VR paradigm }\end{array}$ \\
\hline & & & & & $\begin{array}{l}\text { Bi. lat. anterior insula, } \\
\text { ventral striatum, pre-SMA, } \\
\text { It. subthalamic nucleus }\end{array}$ & $\begin{array}{l}\text { Lower activation during cognitive } \\
\text { load condition while stepping in } \\
\text { FoG group }\end{array}$ \\
\hline \multirow[t]{5}{*}{ Shine et al., 2013b } & \multirow{5}{*}{$\begin{array}{l}\text { Stop-signal task in a VR } \\
\text { environment to navigate a } \\
\text { corridor using foot pedals. } \\
\text { Cognitive load modulated by } \\
\text { Stroop task. Older adults with } \\
\text { PD, with or without FoG }\end{array}$} & \multirow[t]{5}{*}{ Stepping } & \multirow[t]{5}{*}{ fMRI } & \multirow[t]{5}{*}{ No } & $\begin{array}{l}\text { Lft CCN and ventral } \\
\text { attention network }\end{array}$ & $\begin{array}{l}\text { Activation in both groups during } \\
\text { task performance }\end{array}$ \\
\hline & & & & & $\begin{array}{l}\text { Bilateral cognitive control } \\
\text { network }\end{array}$ & $\begin{array}{l}\text { Increased connectivity in both } \\
\text { groups during task performance }\end{array}$ \\
\hline & & & & & Motor network & $\begin{array}{l}\text { Activation during high cognitive } \\
\text { load condition, to lesser extent in } \\
\text { FoG group }\end{array}$ \\
\hline & & & & & $\begin{array}{l}\text { Motor network and left } \\
\text { CCN }\end{array}$ & $\begin{array}{l}\text { Increased connectivity during high } \\
\text { cognitive load }\end{array}$ \\
\hline & & & & & $\begin{array}{l}\text { Basal ganglia network and } \\
\mathrm{CCN} \text { in each hemisphere }\end{array}$ & $\begin{array}{l}\text { Decoupling in FoG group, } \\
\text { associated with freezing event }\end{array}$ \\
\hline \multirow[t]{2}{*}{ Takeuchi et al., 2016} & \multirow[t]{2}{*}{$\begin{array}{l}\text { Walking while playing on smart } \\
\text { phone }\end{array}$} & \multirow[t]{2}{*}{ OG } & \multirow[t]{2}{*}{ fNIRS } & \multirow[t]{2}{*}{ Yes } & \multirow[t]{2}{*}{ PFC } & $\begin{array}{l}\text { No difference in activation during } \\
\text { smartphone use while walking } \\
\text { between young and old groups }\end{array}$ \\
\hline & & & & & & $\begin{array}{l}\text { Differential activation in old and } \\
\text { young groups correlated to } \\
\text { walking acceleration, step time, } \\
\text { and game mistakes }\end{array}$ \\
\hline
\end{tabular}

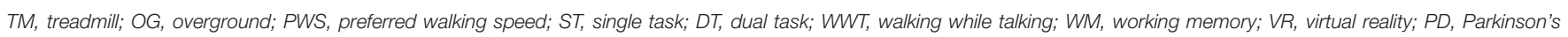

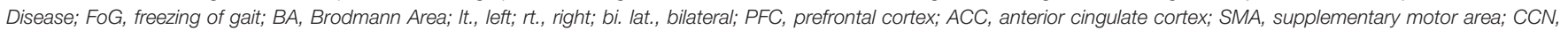
cognitive control network.

signal amplitude was enhanced in the orbital gyrus and medial frontal gyrus, the area of the brain responsible for processing of environmental stimuli. Also, during the performance phase (stepping over the obstacle) enhanced EEG signal amplitude was observed in the superior frontal gyrus, the brain area for monitoring motor performance. Presacco et al. (2012) also observed differential brain activity during different phases of the walking cycle. Utilizing EEG signal captured while subjects walked on a treadmill using visual feedback to avoid stepping on a white line on the treadmill belt, the authors found that the spectral power and signal lag served as inputs into a model that allowed for successful prediction of gait kinematics. Varghese et al. (2016) investigated the predictive nature of dynamic balance control by instructing subjects to laterally shift their weight and laterally step with and without preloading their non-stepping leg. The movement related potential (MRP) due to the lateral weight shift, the anticipatory postural adjustment (APA), was studied by giving the subjects an auditory cue to take a lateral step. Varghese et al. (2016) found a MRP and ERD of mu and beta bands prior to both the APA and the onset of foot-off 
TABLE 7 | Brain activity due to sensory challenges to dynamic balance control.

\begin{tabular}{|c|c|c|c|c|c|c|}
\hline Name, year & Balance challenge & TM or OG & Modality & Mobile & $\begin{array}{l}\text { Spatial } \\
\text { information }\end{array}$ & Brain activity \\
\hline \multirow[t]{2}{*}{ Clark et al., 2014a } & $\begin{array}{l}\text { Sensory enhancement (textured insoles } \\
\text { or bare feet) in older adults }\end{array}$ & TM vs. OG & fNIRS & No & Bilateral PFC & $\begin{array}{l}\text { Reduction in activation for textured insole } \\
\text { and OG conditions }\end{array}$ \\
\hline & & & & & & Decrease in activity in no shoe walking \\
\hline Clark et al., 2014b & Dim lighting while walking in older adults & OG & fNIRS & No & PFC & $\begin{array}{l}\text { Increased activation during preparation and } \\
\text { performance phase }\end{array}$ \\
\hline Haefeli et al., 2011 & Please refer to Table 5 & & & & & \\
\hline
\end{tabular}

TM, treadmill; OG, overground; PFC, prefrontal cortex.

during stepping in the fronto-central cortical areas. However, prior to the APA and during lateral weight shift, there was no difference in brain activity, suggesting cortical activity involved in predictive balance control is independent of context (weight shift vs. lateral step).

One study utilized an fMRI paradigm, applying various external loads during stepping movements in an fMRI to simulate ground reaction forces experienced during real walking (Jaeger et al., 2016). In the zero unloaded condition, activation was observed in the supplementary motor area, superior occipital gyrus. When $20 \%$ of the subject's body weight was applied, primary somatosensory cortex (S1)/Primary motor cortex (M1), vermis, and thalamus activation was observed. Lastly, at a higher load condition ( $40 \%$ of body weight), activation was seen in the insula, vermis, middle occipital gyrus, precuneus secondary somatosensory cortex (S2), thalamus, superior occipital gyrus.

\section{Cognitive Challenges}

Twenty studies used cognitive dual-task paradigms to challenge dynamic balance control (See Table 6). Shine et al. (2013a,b) used fMRI-compatible steppers and a virtual reality hallway to evaluate walking in Parkinson's disease patients with and without FoG. Shine et al. (2013a) found activation of the cognitive control network (bilateral posterior parietal cortices, midline pre-supplementary motor area, bilateral anterior insula, medial temporal lobes, extra-striate visual cortex) in Parkinson's disease patients with and without FoG while walking. However, when cognitive load was modulated by a Stroop task, the FoG group had lower activation of the anterior insula, ventral striatum, pre-supplementary motor area, and subthalamic nucleus in FoG group compared to non-FoG group.

Shine et al. (2013b) found that Parkinson's patients, both with and without FoG, used left cognitive control network (CCN) (left prefrontal cortex, dorsolateral prefrontal cortex, ventrolateral prefrontal cortex) and ventral attention network (anterior insula, dorsal cingulate) and exhibited increased connectivity between the bilateral cognitive control networks. There was increased connectivity of the motor network (pre and post-central gyrus, right supplementary motor area) and left CCN when walking with high cognitive load. Lastly, there was decoupling of the basal ganglia network (caudate, rostral cingulate) and $\mathrm{CCN}$ in each hemisphere in the FoG group which were associated with the occurrence of motor arrests, indicating impaired communication between these networks in FoG. Shine et al. (2013a,b) observed activation of brain regions in the locomotor pathways. However, they also observed activation and connectivity with attention and cognitive control networks required to perform cognitive tasks. Additionally, impaired connectivity seen in FoG provides evidence toward the use of compensation mechanisms and/or additional brain regions in walking in those with neurological disorders.

Thirteen studies utilized fNIRS to investigate cognitive challenges during dynamic balance control, focusing on activation of the prefrontal cortex, supplementary motor area, and premotor cortex. Holtzer et al. (2011) and Holtzer et al. (2015) found increased activation of the prefrontal cortex during a walking while talking task compared to normal walking conditions in older adults. Holtzer et al. (2016) used a similar task paradigm in healthy controls and patients with neurological gait abnormalities, finding that increased prefrontal cortex activation in healthy controls was correlated with high cognitive performance and slow gait speed. In addition, increased prefrontal cortex activation in the group with neurological gait abnormality correlated with low cognitive performance and fast gait speed. Osofundiya et al. (2016) observed higher prefrontal cortex oxygenation levels during complex ambulatory tasks (walking while talking and precision stepping). Doi et al. (2013) also found increased prefrontal cortex activation during a verbal fluency task while walking compared to single task (ST) condition. Using a verbal fluency task, Clark et al. (2014b) found an increase in prefrontal cortex activation compared to single-task walking. In a walking while counting dual-task condition, Al-Yahya et al. (2016) found increased activation of the prefrontal cortex compared to single task walking in older adults with chronic stroke. Lu et al. (2015) found increased activation of the left prefrontal cortex, supplementary motor area, and premotor cortex during walking while subtracting conditions and that increased premotor cortex and supplementary motor area activation were correlated with declines in gait performance. Similarly, increased difficulty of a counting dual-task increased anterior prefrontal cortex activity (Mirelman et al., 2014). Beurskens et al. (2014) used visual and verbal memory demand dual-task conditions while monitoring prefrontal cortex activation in elderly and young subjects. Similar to Holtzer et al. (2011) and Doi et al. (2013), the dual-task condition led to an increase in prefrontal cortex activation in the elderly subjects. However, in young adults, there was a smaller increase 
in prefrontal cortex activation from single task to dual-task conditions.

More complicated paradigms have also been used to investigate brain activity in walking or stepping. Huppert et al. (2013) required subjects to step left or right according to incongruent information (conflicting location and direction of arrow on screen) or congruent information (location and arrow matched), and found increased activation in dorsolateral prefrontal cortex, premotor cortex, supplemental motor area, and precentral gyrus in incongruent trials, which require more attentional control. Lin and Lin (2016) had subjects walk over ground on wide, narrow, or obstacle pathways and with or without a cognitive load (n-back task), and found a decrease in prefrontal cortex activation at higher cognitive loads, similar to Beurskens et al. (2014) and Shimada et al. (2013). Lastly, Takeuchi et al. (2016) observed no difference in prefrontal cortex activation between young and old groups while they played a game on their smartphone while walking. However, differential activation patterns in the right, left, and middle prefrontal cortex were observed to be correlated with gait speed, game mistakes, and step timing in the old and young groups.

Although these fNIRS studies investigate a range of cognitive dual-task conditions using both over ground and treadmill balance paradigms, there is no agreement on the activation of prefrontal cortex, supplementary motor area, and premotor cortex during dual-task conditions. Some studies found an increase in activation in dual-task conditions (Holtzer et al., 2011; Doi et al., 2013; Clark et al., 2014b; Al-Yahya et al., 2016), while others found a decrease (Shimada et al., 2013; Beurskens et al., 2014; Lin and Lin, 2016). In addition, although aging negatively affects balance control, Takeuchi et al. (2016) did not find a difference in prefrontal cortex activation between young and older adults while playing a game and walking.

Seven studies utilized EEG paradigms to investigate the impact of cognitive challenges on dynamic balance control. In a dual-task condition with a cognitive interference task, Beurskens et al. (2016) found a decrease in alpha band power over the $\mathrm{Cz}$ electrode and beta activity over the $\mathrm{FCz}$ and $\mathrm{Cz}$ electrodes compared to normal walking. However, beta band power increased during the cognitive dual-task over the $\mathrm{FPz}$ and Fz electrodes. Kline et al. (2014) had young healthy subjects perform a Brooks spatial working memory (WM) task at different treadmill speeds and found that there was an increase in alpha power prior to stimulus presentation followed by a decreased in alpha power during memory coding in the somatosensory association cortex. A decrease in theta power around memory encoding in the right superior parietal lobule and posterior cingulate cortex was also observed. Additionally, BA 7, BA 31, BA 5, and 6 exhibited power fluctuations time-locked to memory encoding during cognitive tasks. However, no distinct changes in brain activity or working memory task performance were observed due to different walking speeds. De Sanctis et al. (2014) evaluated the impact of walking on a go/no-go task that requires response inhibition in young adults, finding an increase in P200 amplitude in walking conditions (occipital lobe). A reduced $\mathrm{N} 200$ amplitude (at $\mathrm{FCz}, \mathrm{Cz}$, and $\mathrm{CPz}$ ) and $\mathrm{P} 300$ amplitude (at $\mathrm{CPz}$ ) was observed on trials requiring inhibition while walking as compared to sitting. Increased P300 amplitude and decreased latency was observed in faster walking conditions (at FCz). These differences in ERPs were not accompanied by performance decrements in dual-task conditions, suggesting the use of compensation mechanisms to appropriately allocate attentional resources to perform both tasks (De Sanctis et al., 2014). Malcolm et al. (2015) also used a go/no-go task in young and older adults while walking or sitting, finding a decreased N200 amplitude for dual-task condition and earlier P300 latency over the $\mathrm{Cz}, \mathrm{FCz}$, and $\mathrm{CPz}$ electrodes in young adults, similar to De Sanctis et al. (2014). Young adults exhibited a decreased N200 latency, while older adults showed an increase in P300 amplitude, indicating that older adults may have less flexibility of resource allocation in multi-task conditions (De Sanctis et al., 2014). Lau et al. (2014) investigated effective connectivity of the sensorimotor cortex and non-sensorimotor areas of the brain while subjects stood or walked on a treadmill with or without a cognitive challenge. They found that the effective connectivity of sensorimotor cortex was weaker for walking than standing, regardless of dual-task condition, which may point to a more automatic nature of walking execution. However, effective connectivity of non-sensorimotor areas (prefrontal cortex, posterior parietal cortex, and ACC) was stronger in the cognitive dual-task condition for walking than standing.

\section{Sensory Challenges}

The three studies investigating sensory challenges to balance control all observed modulation in prefrontal cortex activity (Haefeli et al., 2011; Clark et al., 2014a,b) (See Table 7). In a dimly lit walking environment, there was an increase in prefrontal cortex activity during preparation and performance of the walking task compared to a regularly lit condition (Clark et al., 2014b). While it has been shown that steady-state walking in older populations is less automatic and increases the need for attentional control and cognitive processes compared to younger populations, Clark et al. (2014a) had older adults with mild mobility deficits walk and mild somatosensory deficits walk on a treadmill and over ground while wearing normal shoes, and under enhanced somatosensory conditions wearing textured insoles, and with no shoes. There was a reduction in prefrontal cortex activity when subjects wore textured insoles compared to normal shoes for both treamill and overground walking. Also, walking with no shoes reduced prefrontal cortex activity for treadmill walking only compared to walking with normal shoes. Enhancing somatosensory information led to a reduction in prefrontal activation compared to control conditions, suggesting a more automatic process is being used perform the walking task. In contrast, under degraded visual conditions, Clark et al. (2014b) and Haefeli et al. (2011) observed increased prefrontal cortex activity.

\section{Studies Selected for RQ3 Movement Artifact Identification and Removal}

Eight EEG studies focused on the identification and/or removal of movement artifact from the brain signal collected while walking (see Table 8). Gwin et al. (2010) used a visual oddball paradigm while subjects walked or ran on a treadmill to elicit 
TABLE 8 | Neuroimaging studies investigating feasibility EEG signal acquisition during dynamic balance control tasks.

\begin{tabular}{|c|c|c|c|c|c|c|}
\hline Name, year & Balance challenge & TM or OG & Modality & Mobile & Spatial information & Analysis \\
\hline Gramann et al., 2010 & $\begin{array}{l}\text { Visual oddball response } \\
\text { task while } \\
\text { standing/walking }\end{array}$ & TM Fixed & EEG & No (tether) & $\mathrm{Fz}, \mathrm{Cz}, \mathrm{Pz}$ & $\begin{array}{l}\text { Identification of P300 and N100 } \\
\text { amplitudes due to visual oddball } \\
\text { stimulus }\end{array}$ \\
\hline Gwin et al., 2010 & $\begin{array}{l}\text { Visual oddball task while } \\
\text { walking or running }\end{array}$ & TM Fixed & $\mathrm{EEG}$ & No & Mediofrontal clusters & $\begin{array}{l}\text { Identification of gait-related } \\
\text { artifact in ERP during running }\end{array}$ \\
\hline Oliveira et al., 2016 & $\begin{array}{l}\text { Auditory oddball task } \\
\text { seated and walking }\end{array}$ & TM Fixed & EEG & Yes & $\begin{array}{l}\mathrm{Fpz}, \mathrm{F} 3, \mathrm{Fz}, \mathrm{F} 4, \mathrm{C} 3, \mathrm{Cz} \\
\mathrm{C} 4, \mathrm{P} 3, \mathrm{Pz}, \mathrm{P} 4, \mathrm{O} 1, \mathrm{O} 2\end{array}$ & $\begin{array}{l}\text { Epoch rejection rate, } \\
\text { pre-stimulus noise, } \\
\text { signal-to-noise ratio, P300 } \\
\text { amplitude }\end{array}$ \\
\hline Lau et al., 2012 & $\begin{array}{l}\text { Response to target } \\
\text { stimulus while walking }\end{array}$ & TM Fixed & EEG & No & Global & $\begin{array}{l}\text { Identification of P300 response } \\
\text { in walking condition }\end{array}$ \\
\hline Castermans et al., 2014 & Barefoot walking & TM Fixed & EEG & No & Cz, Oz, T8 & $\begin{array}{l}\text { Harmonics in accelerometer and } \\
\text { EEG signals (delta, theta, alpha } \\
\text { bands) }\end{array}$ \\
\hline Kline et al., 2015 & $\begin{array}{l}\text { Walking at set speeds } \\
\text { with silicone cap }\end{array}$ & TM Fixed & EEG & Yes & $\begin{array}{l}\mathrm{E} 12, \mathrm{~A} 19, \mathrm{G} 11, \mathrm{C} 19, \\
\mathrm{~A} 1\end{array}$ & $\begin{array}{l}\text { Movement artifact varies with } \\
\text { speed, subject and electrode } \\
\text { location }\end{array}$ \\
\hline \multirow[t]{2}{*}{$\begin{array}{l}\text { Nathan and Contreras-Vidal, } \\
2016\end{array}$} & Walking at set speed & TM Fixed & EEG & Yes & $\mathrm{Cz}, \mathrm{Oz}, \mathrm{T} 8$ & $\begin{array}{l}\text { No large amplitude spikes in } \\
\text { spectral signals corresponding } \\
\text { stepping frequency } \\
\text { (accelerometer signal) }\end{array}$ \\
\hline & & & & & & $\begin{array}{l}\text { Strong wavelet coherence } \\
\text { between delta band and } \\
\text { accelerometer for higher walking } \\
\text { speeds. }\end{array}$ \\
\hline
\end{tabular}

TM, treadmill; ERP, event related potential; ICA, Independent Component Analysis.

an ERP. In the walking condition, the ERP was nearly identical before and after movement artifact removal. However, in the running condition, the ERP was only identifiable after using a template regression artifact removal process. Gramann et al. (2010) also investigated the feasibility of using more mobile EEG hardware (a single tether connected electrodes to equipment) while subjects were walking or standing. The authors were able to identify the P300 and N100 ERP components evoked by a visual oddball paradigm over the $\mathrm{Cz}, \mathrm{Fz}$, and $\mathrm{Pz}$ electrodes. Oliveira et al. (2016) aimed to establish a protocol to validate the efficacy of EEG hardware and software systems in mobile neuroimaging using an auditory oddball paradigm in sitting and walking conditions. The authors recommended using epoch rejection rate, pre-stimulus noise, signal-to-noise ratio, and amplitude variance across the P300 event window to evaluate EEG hardware systems and artifact identification and removal efficacy in walking studies. In a different approach, Lau et al. (2012) used a weighted phase lag index across all channels and recovered a P300 response to a target stimulus while subjects stood or walked on a treadmill.

Four studies have focused on characterizing the walking related movement artifact. Castermans et al. (2014) used barefoot walking on a treadmill while collecting both EEG and accelerometer signals. The accelerometer was mounted on the subject's head and showed increased activity corresponding to walking events (heel-strike and double support phase). Additionally, analysis of the EEG and accelerometer signals showed harmonics up to $15 \mathrm{~Hz}$ in the EEG signal, with the potential to impact the delta, theta and alpha frequency bands. Furthermore, the signal correlation varied for each of the three EEG electrode locations $(\mathrm{Cz}, \mathrm{Oz}, \mathrm{T} 8)$, suggesting that a uniform filtering method could not be used across all scalp electrodes (Castermans et al., 2014). Kline et al. (2015) and Snyder et al. (2015) used a silicone swim cap to block all electrocortical activity, thus measuring only movement artifact while subjects walked on a treadmill at different speeds. Like Castermans et al. (2014) and Kline et al. (2015) collected accelerometer data, however, there was poor correlation between the EEG and accelerometer signals. Furthermore, there was variation in movement artifact at different walking speeds, electrode locations, and in each subject. Snyder et al. (2015) used independent component analysis (ICA) and dipole fitting to localize movement artifact. ICA is an advanced mathematical tool that separates a signal into statistically independent components, potentially separating the EEG signal into independent cerebral sources and artifact sources (Makeig et al., 1996). Dipole fitting of the pure movement artifact signal accurately localized 99\% of the independent components (ICs) originating outside the brain. The remaining $1 \%$ of ICs remained in the signal and had similarities with neural sources, revealing opportunities 
to completely remove movement artifact during walking. In contrast to the focus of Kline et al. (2015) and Snyder et al. (2015) on movement artifact only, Nathan and Contreras-Vidal (2016) analyzed the EEG signal and its relation to an accelerometer signal which was collected while subjects walked at various speeds. In this study, there were no large spectral amplitude spikes corresponding to the stepping frequency, which was obtained from the accelerometer signal. This finding refutes the analysis in Castermans et al. (2014). Wavelet coherence analysis revealed strong coherence between the EEG signal within the delta band and the accelerometer for higher walking speeds, which suggests the emergence of movement artifact within the EEG signal. However, after artifact subspace reconstruction, an automated artifact rejection process that uses baseline data and principal component analysis to remove transient and high amplitude artifact (i.e., muscle movements), this delta band coherence was not observed in the average subject data. This study suggests that movement artifact may not contaminate EEG data collected at slower walking speeds when using mobile neuroimaging equipment (Nathan and Contreras-Vidal, 2016).

\section{Signal Processing of fNIRS Data}

Table 9 summarizes the pre-processing and movement artifact removal methods of 20 studies using fNIRS for neuroimaging. Two studies used wavelet-minimum description length detrending algorithms to remove global trends including artifacts due to respiration, heartbeat, and vasoconstriction. Five studies used principal (PCA) or independent (ICA) component analysis, or their combination, to remove environmental and equipment noise and signal drift. However, the majority of these studies did not use computational methods to remove artifacts from the acquired signal.

\section{Signal Processing of EEG Data}

Table 10 summarizes the pre-processing, spatial filtering, and movement artifact identification and removal methods used by the 54 EEG studies included in this review. For data preprocessing, all studies except three reported using high-pass, lowpass, or bandpass filters to exclude certain frequency ranges. Gwin et al. (2010) described criteria for removing noisy channels prior to data analysis: Standard deviation $(S D)>1,000 \mu \mathrm{V}$, kurtosis $>5 S D$ from mean, or poor correlation $(r<0.4)$ with neighboring channels for $>1 \%$ of time samples. Ten additional studies used these criteria for removing noisy channels prior to further analysis. Twenty-five studies used spatial filtering techniques, including Laplacian estimation (3), referencing to a common average (21), and bi-lateral referencing (1).

The literature reports a multitude of techniques to identify and remove ocular, muscular, and/or movement artifact during dynamic balance tasks, ranging from visual inspection (10) to sophisticated computational techniques. Petrofsky and Khowailed (2014) and Tse et al. (2013) used logistic discrimination function analyses tuned using an EEG database from sleep-deprived adults to identify eye blink regions, which were subsequently replaced by mean wavelet coefficients from nearby non-contaminated regions (Berka et al., 2007). Three studies defined and rejected time periods having substantial artifact using a criterion $(>0.8)$ on the z-transformed power across all channels (Gwin et al., 2011; Sipp et al., 2013; Lau et al., 2014). Gwin et al. (2011) presented a moving average artifact removal method for EEG data collected during walking. Here, time-warped strides were averaged before and after a specific foot strike event. Then this time-warped average stride data was subtracted from the new data for a current stride. This was also used in Kline et al. (2015) explored the combination of this moving average approach with a wavelet technique that removed signal content at frequencies below $8 \mathrm{~Hz}$ and applied the wavelets to the whole stride using Daubechies four wavelets.

However, approximately half the studies (i.e., a total of 23) used conventional ICA or adaptive mixture ICA (AMICA) to identify and remove artifacts from EEG data collected during walking. Hülsdünker et al. (2015) and Hülsdünker et al. (2016) identified and removed ocular or muscular artifacts based on the cortical mapping, frequency spectrum, and time course components using ICA. Bruijn et al. (2015) described the following criteria for categorizing and removing components not associated with brain activity: Muscle artifact $(50-100 \mathrm{~Hz}$ mean power larger than that in the beta and/or alpha bands), eye-blink artifacts (median frequency $<3 \mathrm{~Hz}$ and the topo map corresponded to eye components), and movement artifacts (frequency spectrum at the harmonics of stride frequency). After performing ICA or AMICA, several studies also used a source localization algorithm, DIPFIT, to refine artifact identification and removal. Gramann et al. (2010) evaluated each independent component for location within the head model and evaluated the residual variance between the scalp projection through a head model and scalp map. Gwin et al. (2011) used a similar approach but excluded components if the current dipole model to scalp accounted for less than $80 \%$ of the scalp variance - criteria used by six other studies (Sipp et al., 2013; Kline et al., 2014; Lau et al., 2014; Bradford et al., 2015; Bulea et al., 2015; Snyder et al., 2015). Lastly, 6 studies used PCA to identify and remove movement artifact (Bulea et al., 2014, 2015; Huang et al., 2014; Marlin et al., 2014; Luu et al., 2016; Nathan and Contreras-Vidal, 2016).

\section{GENERAL DISCUSSION AND CONCLUSION}

This study reviewed 83 articles using neuroimaging modalities to investigate the neural correlates underlying static and dynamic human balance control, with aims to support future mobile neuroimaging research in the balance control domain. Images demonstrating the use of mobile neuroimaging modalities integrated with a dynamic balance control tasks can be found in Kline et al. (2015). Likewise, examples of study paradigms using non-mobile neuroimaging modalities within this domain can be found in Chang et al. (2016) and Gramann et al. (2010).

This review found that static balance control was largely examined with sensory or mechanical balance paradigms. There were relatively few static paradigms that utilized cognitive challenges to study the neural components of balance. Additionally, all but one static balance study using sensory challenges, such as using open and closed eye conditions, 
TABLE 9 | Signal processing and artifact removal methods for fNIRS studies.

\begin{tabular}{|c|c|c|}
\hline Name, year & Pre-processing & Removal of movement artifact \\
\hline Al-Yahya et al., 2016 & Low-pass filter at $0.67 \mathrm{~Hz}$ cutoff frequency & \\
\hline Beurskens et al., 2014 & Gaussian/Hemodynamic response function lowpass filter & Wavelet-minimum description length algorithm \\
\hline Caliandro et al., 2015 & Low pass filter $(0.1 \mathrm{~Hz})$ & \\
\hline Doi et al., 2013 & Low pass filter $(0.5 \mathrm{~Hz})$ & \\
\hline Fujita et al., 2016 & Low pass filter $(0.5 \mathrm{~Hz})$ & \\
\hline Holtzer et al., 2015, 2016 & Low pass filter (FIR, $0.14 \mathrm{~Hz})$ & Inspection to remove signal artifact \\
\hline \multirow[t]{2}{*}{ Huppert et al., 2013} & Low pass filter $(0.8 \mathrm{~Hz})$ & \\
\hline & Series of discrete cosine transform terms & \\
\hline Karim et al., 2013 & Series of discrete cosine transform terms & \\
\hline Kim et al., 2016 & & Gaussian smoothing. Wavelet minimum description length algorithm. \\
\hline Kurz et al., 2012 & High pass filter $(0.01 \mathrm{~Hz})$ & PCA, removing components $<0.25$ correlation with reference waveform \\
\hline Lin and Lin, 2016 & Low pass filter (FIR, $0.2 \mathrm{~Hz})$ & \\
\hline Lu et al., 2015 & $\begin{array}{l}\text { Removal of noisy channels using coefficient of variation } \\
\text { Bandpass filter }(0.01-0.2 \mathrm{~Hz})\end{array}$ & PCA and Spike Rejection \\
\hline Maidan et al., 2015 & Low pass filter (FIR, $0.14 \mathrm{~Hz}$ ) & \\
\hline Mihara et al., 2008 & High pass filter $(0.05 \mathrm{~Hz})$ & Gaussian function \\
\hline Mihara et al., 2012 & High pass filter $(0.03 \mathrm{~Hz})$ & \\
\hline Mirelman et al., 2014 & Low pass filter (FIR, 0.14 Hz) & \\
\hline Takeuchi et al., 2016 & Bandpass filter $(0.01-0.5 \mathrm{~Hz})$ & Rapid changes in oxyHb concentration were removed \\
\hline
\end{tabular}

FIR, finite impulse response; ICA, independent component analysis; PCA, principle component analysis; SD, standard deviation.

were performed on healthy, young adults. Analysis of brain activity during standing balance control included perturbation evoked ERPs and frequency analysis, with findings of increased activation during balance challenges, regardless of challenge type (sensory, cognitive, or mechanical). Activation of the prefrontal cortex (PFC), supplementary motor area (SMA), and Premotor cortex (PMC) frequently occurred in response to the static balance challenges. Although more common in dynamic balance control studies, seven of the static balance control studies invoking mechanical perturbations used advanced signal processing methodologies such as ICA to reduce movement artifacts (Mochizuki et al., 2009a; Smith et al., 2012, 2014; Marlin et al., 2014; Varghese et al., 2014, 2015; Hülsdünker et al., 2016).

In dynamic balance control paradigms, there were many cognitive dual-task conditions and very few sensory and mechanical balance challenges. The mechanical balance challenges included obstacles or challenge walking scenarios, such as using a balance beam. However, none of these studies used surface perturbations as seen in the static paradigms. Lastly, almost a third of the dynamic balance tasks included over ground walking instead of treadmill walking. Analysis of brain activity included activation of the prefrontal cortex, supplementary motor area, and SMC and frequency band analysis at different time points in gait cycle and task execution process. These areas of brain activation overlap with the direct and indirect locomotor pathways proposed by la Fougere et al. (2010). Given the dual-task nature of dynamic balance control challenges, it is not surprising that there is involvement of the prefrontal cortex, which is associated with the indirect locomotor pathway (la Fougere et al., 2010; Zwergal et al., 2013; Hamacher et al., 2015). Lastly, the majority of the EEG studies in this review used advanced signal processing methods to identify and remove movement artifact in the acquired brain signal, specifically by using ICA. Several studies have explicitly investigated and attempted to characterize the movement artifact due to steadystate walking and the feasibility of using these advanced signal processing methods for research in this domain.

\section{Mobile Neuroimaging Methods in Static and Dynamic Balance Control}

Mobile neuroimaging was used in eight studies to investigate the brain activity associated with balance challenge tasks. Five studies used wireless EEG systems and dynamic balance control paradigms on treadmills (Bulea et al., 2015; Kline et al., 2015; Beurskens et al., 2016; Nathan and Contreras-Vidal, 2016; Oliveira et al., 2016), one study used wireless EEG in static balance control (Bulea et al., 2014), and two investigated dynamic balance control using paradigms pairing mobile fNIRS systems and over ground walking ( $\mathrm{Lu}$ et al., 2015; Takeuchi et al., 2016). As most of these mobile neuroimaging studies paired walking with a cognitive or motor task, it is clear that the broad range of human balance control paradigms have not been fully 
TABLE 10 | Signal processing and artifact removal methods for EEG studies.

\begin{tabular}{|c|c|c|c|}
\hline Name, year & Pre-processing & Spatial filtering & Movement artifact removal \\
\hline \multirow[t]{2}{*}{ Adkin et al., 2008} & Bandpass filter (0.1-10 kHz) & & \\
\hline & Low-pass filter (30 Hz cutoff) & & \\
\hline Beurskens et al., 2016 & Bandpass filter $(0.5-45 \mathrm{~Hz})$ & Reference using common reference & $\begin{array}{l}\text { Visual inspection and semiautomatic } \\
\text { artifact rejection }( \pm 100 \mu \mathrm{V})\end{array}$ \\
\hline Bruijn et al., 2015 & Band-stop filter $(50,100,150$, and $250 \mathrm{~Hz})$ & & \\
\hline \multirow[t]{2}{*}{ Bulea et al., 2014} & High pass filter (Butterworth, $0.05 \mathrm{~Hz}$ ) & Common average reference & Artifact subspace reconstruction (uses \\
\hline & Bandpass filter (Butterworthy, $0.1-4 \mathrm{~Hz}$ ) & & PCA to clean data) \\
\hline \multirow[t]{2}{*}{ Bulea et al., 2015} & High pass filter at $1 \mathrm{~Hz}$ & Re-referenced to common average of & Artifact subspace reconstruction (uses \\
\hline & Power line noise remove & & PCA to clean data). AMICA and DIPFIT \\
\hline \multirow[t]{2}{*}{ De Sanctis et al., 2014} & Bandpass filter $(0.05-100 \mathrm{~Hz})$ & \multirow{2}{*}{$\begin{array}{l}\text { Re-referenced offline to an average } \\
\text { reference }\end{array}$} & \multirow[t]{2}{*}{ Automatic artifact rejection $( \pm 100 \mu \mathrm{V})$} \\
\hline & Bandpass filter $(0.5-30 \mathrm{~Hz})$ & & \\
\hline Del Percio et al., 2007, 2009 & Bandpass filter $(0.01-100 \mathrm{~Hz})$ & Laplacian estimation & $\begin{array}{l}\text { Autoregressive method to remove } \\
\text { ocular artifact }\end{array}$ \\
\hline \multirow[t]{2}{*}{ Gramann et al., 2010} & High pass filter $(1 \mathrm{~Hz})$ & \multirow{2}{*}{$\begin{array}{l}\text { Re-referenced offline to an average } \\
\text { reference }\end{array}$} & \multirow[t]{2}{*}{ ICA, AMICA and DIPFIT } \\
\hline & Noisy channels removed & & \\
\hline \multirow[t]{2}{*}{ Gwin et al., 2010} & High pass filter $(1 \mathrm{~Hz})$ & \multirow{2}{*}{$\begin{array}{l}\text { Re-referenced offline to an average } \\
\text { reference }\end{array}$} & \multirow[t]{2}{*}{ Moving average method } \\
\hline & Noisy channels removed & & \\
\hline \multirow[t]{2}{*}{ Gwin et al., 2011} & High pass filter $(1 \mathrm{~Hz})$ & \multirow{2}{*}{$\begin{array}{l}\text { Re-referenced offline to an average } \\
\text { reference }\end{array}$} & \multirow{2}{*}{$\begin{array}{l}\text { Rejected time periods with substantial } \\
\text { artifact. AMICA and DIPFIT }\end{array}$} \\
\hline & Noisy channels removed & & \\
\hline Jacobs et al., 2008 & Bandpass filter $(0.05-60 \mathrm{~Hz})$ & & \\
\hline \multirow[t]{2}{*}{ Kline et al., 2014} & High pass filter $(1 \mathrm{~Hz})$ & \multirow{2}{*}{$\begin{array}{l}\text { Re-referenced the remaining channels } \\
\text { to an average reference }\end{array}$} & \multirow[t]{2}{*}{ AMICA and DIPFIT } \\
\hline & Noisy channels removed & & \\
\hline \multirow[t]{4}{*}{ Kline et al., 2015} & High pass filter $(1 \mathrm{~Hz})$ & $\begin{array}{l}\text { Re-referenced the remaining channels } \\
\text { to an average reference. }\end{array}$ & Moving average method \\
\hline & & & Wavelets \\
\hline & $\begin{array}{l}\text { Rejected epochs }>3 \text { standard deviations } \\
\text { from the means of the gait event times }\end{array}$ & & Moving Average and Wavelets \\
\hline & & \multicolumn{2}{|l|}{$\begin{array}{l}\text { EEG movement artifact compared to } \\
\text { accelerometer signal }\end{array}$} \\
\hline \multirow[t]{3}{*}{ Lau et al., 2014} & Highpass filter (1 Hz). & \multirow{3}{*}{$\begin{array}{l}\text { Re-referenced the remaining channels } \\
\text { to an average reference }\end{array}$} & Moving average method \\
\hline & Filter line noise $(60 \mathrm{~Hz})$ & & \\
\hline & Noisy channels removed & & \\
\hline Lau et al., 2012 & Highpass filter (1 Hz). & Channels were then re-referenced to an & Weighted Phase Lag Index \\
\hline & Filter around $4+/-2 \mathrm{H}$ & average of the remaining channels. & \\
\hline & Noisy channels removed & & \\
\hline
\end{tabular}




\section{TABLE 10 | Continued}

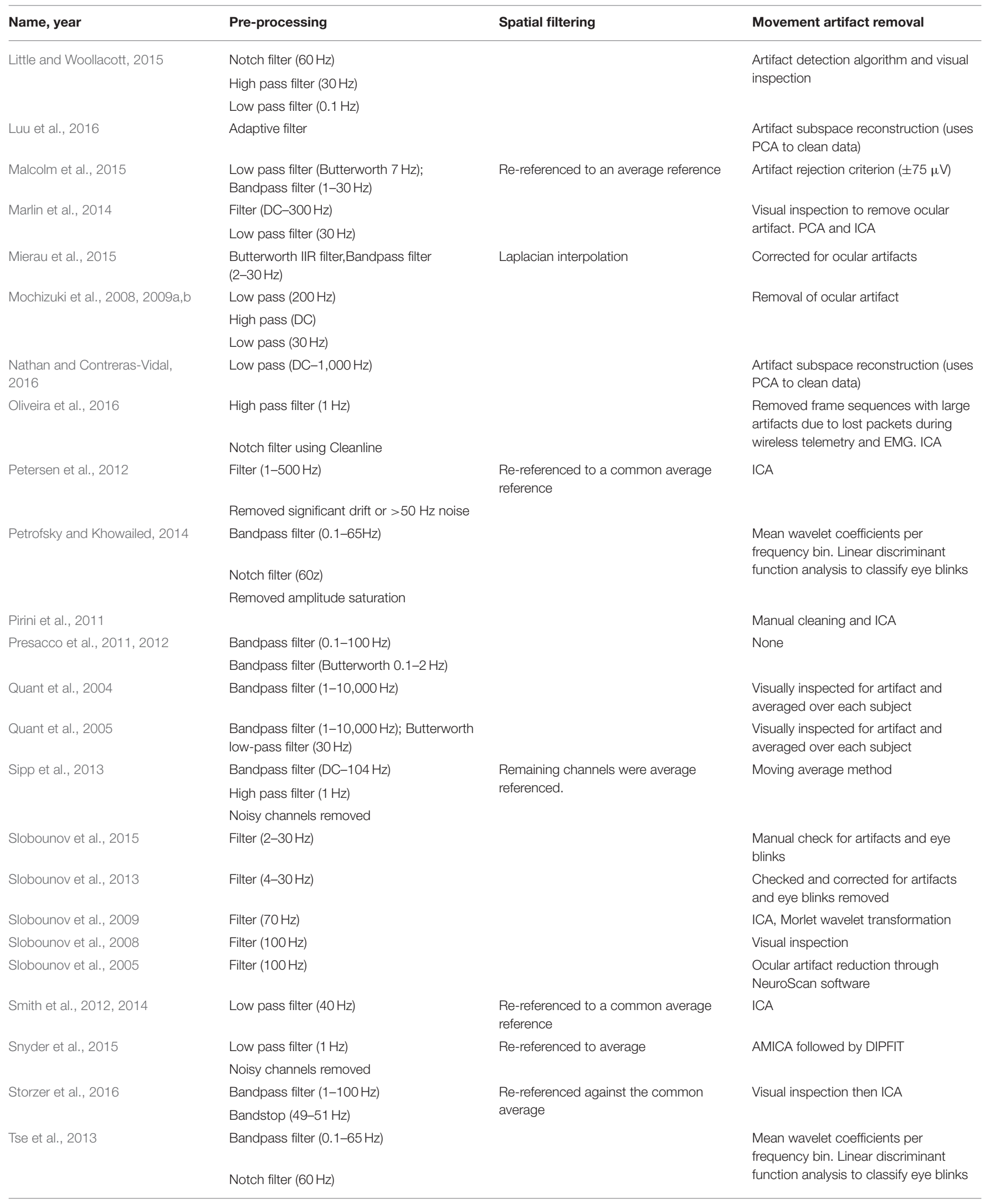


TABLE 10 | Continued

\begin{tabular}{|c|c|c|c|}
\hline Name, year & Pre-processing & Spatial filtering & Movement artifact removal \\
\hline Varghese et al., 2016 & Bandpass filter $(0.05-50 \mathrm{~Hz})$ & & ICA \\
\hline \multirow[t]{2}{*}{ Varghese et al., 2015} & Bandpass filter (DC-300 Hz) & & ICA \\
\hline & Bandpass filter $(2-50 \mathrm{~Hz})$ & & \\
\hline Varghese et al., 2014 & Bandpass filter $(1-30 \mathrm{~Hz})$ & & ICA \\
\hline
\end{tabular}

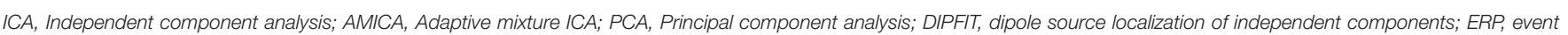
related potential.

investigated with mobile modalities. Given the innovative nature of this mobile technology, this is to be expected.

Interestingly, only two studies investigated brain activity in both static and dynamic balance control tasks (Lau et al., 2012; Mirelman et al., 2014). Neither of these studies used a mechanical perturbation to challenge balance. However, many static balance control paradigms use perturbations that invoke a feet-in-place response in which subjects use only postural sway strategies to maintain upright balance (Adkin et al., 2008). However, perturbations that exceed this feet-in-place threshold, and thereby elicit a stepping response, can potentially be used to develop a deeper understanding of the neural mechanisms involved in the transition between static and dynamic balance control. Two main recommendations for future mobile neuroimaging research include:

1) Researchers utilizing mobile EEG and/or fNIRS systems should focus on pairing these modalities with a broader range of dynamic balance control challenges, such as sensory perturbations. Additionally, the use of these mobile modalities in static balance control challenges is minimal, providing an opportunity for further investigation and direct comparison to findings from tethered neuroimaging systems.

2) Mobile neuroimaging modalities should be paired with balance control paradigms that go beyond a feet-in-place reaction (Slobounov et al., 2009; Varghese et al., 2016). Perturbations that require the subject to maintain balance control in an upright stance but require a stepping response may provide insights into mechanisms required in the transition between static and dynamic balance control.

\section{Multi-imaging Paradigms in Balance Control Domain}

All neuroimaging methods have advantages and disadvantages. By concurrently using multiple imaging modalities within the same study, we could develop a deeper understanding of the temporal and spatial dynamics of brain activity in the balance control domain. Within this review, one study analyzed dynamic balance control through fNIRS and fMRI (Al-Yahya et al., 2016). In this study, real gait was paired with fNIRS methods while isolated ankle movements were paired with fMRI. The latter task excluded this condition from inclusion in this review. Three studies in this review implemented MRI-compatible steppers to allow for active leg movements that closely resemble gait (Shine et al., 2013a,b; Jaeger et al., 2016).
Additionally, both fMRI and fNIRS are indirect, hemodynamic imaging methods that have poor temporal resolution. In contrast, direct, electrocortical modalities such as EEG are known to have high temporal resolution. Within other research domains, such as neural mechanisms of emotion, both fMRI and EEG are used to capitalize on the advantages of both indirect and direct imaging methods. The challenge in the balance control domain is the development of research paradigms that are valid for multiple imaging modalities. This is especially challenging when using immobile methods, such as fMRI, although implementing real-stepping is a possible solution. Real stepping in a supine position, as required by an fMRI, limits the number of balance challenge tasks that can be evaluated, for example to surface perturbations. Although fMRI has a superior spatial resolution as compared to fNIRS, the mobility of the fNIRS hardware provides an advantage in studying the full range of balance challenges. Therefore, future research should investigate paradigms that combine EEG and fNIRS. Simultaneous EEG-NIRS recording systems have been successfully used in language studies, but the combination of electrodes and optodes was not mobile (Wallois et al., 2012). Given the potential of multi-modality neuroimaging within the balance control domain, two main recommendations for future work include:

1) The spatial resolution of fMRI, PET, and SPECT neuroimaging modalities is valuable for elucidating the neural sources involved in balance control. However, future multi-modal studies including one of these modalities should implement an active leg movement paradigm, similar to (Shine et al., 2013a,b; Jaeger et al., 2016), as this more closely resembles real gait as compared to locomotion imagery.

2) Research groups working to improve neuroimaging hardware and software should focus on technical challenges hindering the pairing of fNIRS and EEG modalities. A multi-modal, mobile fNIRS and EEG system could leverage the spatial and temporal resolution of each, providing additional insights into the brain activity involved in balance control tasks.

\section{LIMITATIONS}

This review was limited by several factors:

1. The search databases, terminology, and dates directly impact the literature included in this review. Final searches in all databases were performed on September 1, 2016; therefore, 
this review only includes studies published on or before this date. Additionally, the choice of search terms was based on keywords and terminology in current literature within the neuroimaging and balance control domains. This may have led to exclusion of studies with different terminology or emphasis, including early work on cortical potentials evoked by balance control challenges. Studies by Dietz et al., 1984; Ackermann et al., 1986, for example, characterized the cortical potential occurring after a balance challenge, terming it the perturbation-evoked potential. Several studies included in this review extend the findings of these early papers (Mihara et al., 2007; Adkin et al., 2008; Jacobs et al., 2008; Mochizuki et al., 2008). Therefore, the results of this review are not impacted by the exclusion of these early papers.

2. This review focused only on brain activity during balance control tasks, and did not attempt to analyze muscle activity during these tasks. Electromyographic signals are necessary for motion and, as an indirect indicator of neural activity, are thus involved in maintaining balance control. While correlation between muscle and brain activity may provide additional insights into the mechanisms involved in balance control, analysis of electromyography results was beyond the scope of this review.

\section{FUTURE WORK}

Further analysis of balance control paradigms suggests that there are significant opportunities for innovation in neuroimaging research within this domain, which include:

1) Researchers utilizing neuroimaging modalities in the balance control domain have a clear opportunity to couple these modalities with sensory and mechanical balance challenges, including experimental manipulation of optical flow, vestibular inputs, and conditions that impair multi-sensory integration.

2) There is evidence that cognitive loading in patients with neurological disorders, such as Parkinson's disease, or in advancing age impacts the ability to main upright stance (Wajda and Sosnoff, 2015) and may increase risk of falls. These populations should continue to be included in future research to elucidate the neural mechanisms governing and potential compensatory mechanisms involved in balance control responses.

3) Movement artifact identification and removal is obviously still an issue to be addressed. Recent studies have revealed high inter-subject variability and the difficulty in completely eliminating gait-related movement artifacts from EEG signals (Castermans et al., 2014; Bradford et al., 2015; Kline et al.,

\section{REFERENCES}

Ackermann, H., Diener, H. C., and Dichgans, J. (1986). Mechanically evoked cerebral potentials and long-latency muscle responses in the evaluation of afferent and efferent long-loop pathways in humans. Neurosci. Lett. 66, 233-238. doi: 10.1016/0304-3940(86)90024-8
2015; Snyder et al., 2015; Nathan and Contreras-Vidal, 2016). It is clear that future work should focus on improving techniques and methodologies for signal processing of acquired mobile signals.

4) Engineers focused on the development of mobile neuroimaging hardware have an opportunity to include design elements that will dampen the noise user movement introduces into the signal. Additionally, design engineers should remain aware of human factors considerations during the design process, including hardware usability and user satisfaction for all user groups.

5) Lastly, as mentioned by Oliveira et al. (2016), there is a need for benchmarking mobile neuroimaging acquisition systems, specifically in terms of repeatability, signal quality, and user satisfaction of the various hardware and software systems.

The nine recommendations (two for mobile imaging, two for multi-modal imaging, and five for general balance control domain) put forward in this review provide a foundation for future investigation of neuroimaging within the balance control domain. The relatively recent breakthroughs in mobile neuroimaging paradigms have allowed researchers to investigate brain activity during natural human movement (Gramann et al., 2014). However, it is clear that the application of mobile neuroimaging systems in the human balance control domain is still in its early stages. There remains considerable opportunities in identifying neural mechanisms underlying human balance control and the use of these systems in truly mobile, real-world balance challenges.

\section{AUTHOR CONTRIBUTIONS}

All authors contributed equally to this work by conducting the review and drafting the initial manuscript. EW and JT were responsible for writing and editing the current manuscript under supervision of $\mathrm{CN}$ and JF who oversaw the project and guided it to completion. All authors discussed the results and implications and commented on the manuscript at all stages.

\section{ACKNOWLEDGMENTS}

This work was supported in part by the National Science Foundation (NSF) under Grants IIS-1421948 and BCS-1551688, the University of Carolina at Chapel Hill and North Carolina State Rehabilitation Engineering Core (REC), and the National Institutes of Health (NIH, UL1TR001111). Any opinions, findings, and conclusions or recommendations expressed in this material are those of the authors and do not necessarily reflect the views of the NSF, REC, or NIH. influence of postural threat on the cortical response to unpredictable and predictable postural perturbations. Neurosci. Lett. 435, 120-125. doi: 10.1016/j.neulet.2008.02.018

Adkin, A. L., Quant, S., Maki, B. E., and McIlroy, W. E. (2006). Cortical responses associated with predictable and unpredictable compensatory 
balance reactions. Exp. Brain Res. 172, 85-93. doi: 10.1007/s00221-0050310-9

Alexander, B. H., Rivara, F. P., and Wolf, M. E. (1992). The cost and frequency of hospitalization for fall-related injuries in older adults. Am. J. Public Health 82, 1020-1023. doi: 10.2105/AJPH.82.7.1020

Al-Yahya, E., Johansen-Berg, H., Kischka, U., Zarei, M., Cockburn, J., and Dawes, H. (2016). Prefrontal cortex activation while walking under dual-task conditions in stroke: a multimodal imaging study. Neurorehabil. Neural Repair 30, 591-599. doi: 10.1177/1545968315613864

Aprigliano, F., Martelli, D., Micera, S., and Monaco, V. (2016). Intersegmental coordination elicited by unexpected multi-directional slipping-like perturbations resembles that adopted during steady locomotion. J. Neurophysiol. 115, 728-740. doi: 10.1152/jn.00327.2015

Bauby, C. E., and Kuo, A. D. (2000). Active control of lateral balance in human walking. J. Biomech. 33, 1433-1440. doi: 10.1016/S0021-9290(00)00101-9

Bent, L. R., McFadyen, B. J., and Inglis, T. J. (2002). Visual-vestibular interactions in postural control during the execution of a dynamic task. Exp. Brain Res. 146, 490-500. doi: 10.1007/s00221-002-1204-8

Berka, C., Levendowski, D. J., Lumicao, M. N., Yau, A., Davis, G., Zivkovic, V. T., et al. (2007). EEG correlates of task engagement and mental workload in vigilance, learning, and memory tasks. Aviat. Space Environ. Med. 78, B231-B244.

Beurskens, R., Helmich, I., Rein, R., and Bock, O. (2014). Age-related changes in prefrontal activity during walking in dual-task situations: a fNIRS study. Int. J. Psychophysiol. 92, 122-128. doi: 10.1016/j.ijpsycho.2014.03.005

Beurskens, R., Steinberg, F., Antoniewicz, F., Wolff, W., and Granacher, U. (2016). Neural correlates of dual-task walking: effects of cognitive versus motor interference in young adults. Neural Plast. 2016:8032180. doi: $10.1155 / 2016 / 8032180$

Bove, M., Nardone, A., and Schieppati, M. (2003). Effects of leg muscle tendon vibration on group Ia and group II reflex responses to stance perturbation in humans. J. Physiol. 550(Pt 2), 617-630. doi: 10.1113/jphysiol.2003. 043331

Bradford, J. C., Lukos, J. R., and Ferris, D. P. (2015). Electrocortical activity distinguishes between uphill and level walking in humans. J. Neurophysiol. 115, 958-966. doi: 10.1152/jn.00089.2015

Brauer, S. G., Burns, Y. R., and Galley, P. (2000). A prospective study of laboratory and clinical measures of postural stability to predict community-dwelling fallers. J. Gerontol. Ser. A Biol. Sci. Med. Sci. 55, M469-M476. doi: 10.1093/gerona/55.8.M469

Bruijn, S. M., Van Dieen, J. H., and Daffertshofer, A. (2015). Beta activity in the premotor cortex is increased during stabilized as compared to normal walking. Front. Hum. Neurosci. 9:593. doi: 10.3339/fnhum.2015.00593

Bulea, T. C., Kim, J., Damiano, D. L., Stanley, C. J., and Park, H.-S. (2015). Prefrontal, posterior parietal and sensorimotor network activity underlying speed control during walking. Front. Hum. Neurosci. 9:247. doi: 10.3389/fnhum.2015.00247

Bulea, T. C., Prasad, S., Kilicarslan, A., and Contreras-Vidal, J. L. (2014). Sitting and standing intention can be decoded from scalp EEG recorded prior to movement execution. Front. Neurosci. 8:376. doi: 10.3389/fnins.2014.00376

Caliandro, P., Serrao, M., Padua, L., Silvestri, G., Iacovelli, C., Simbolotti, C., et al. (2015). Prefrontal cortex as a compensatory network in ataxic gait: A correlation study between cortical activity and gait parameters. Restor. Neurol. Neurosci. 33, 177-187. doi: 10.3233/RNN-140449

Castermans, T., Duvinage, M., Cheron, G., and Dutoit, T. (2014). About the cortical origin of the low-delta and high-gamma rhythms observed in EEG signals during treadmill walking. Neurosci. Lett. 561, 166-170. doi: 10.1016/j.neulet.2013.12.059

Chang, C.-J., Yang, T.-F., Yang, S.-W., and Chern, J.-S. (2016). Cortical modulation of motor control biofeedback among the elderly with high fall risk during a posture perturbation task with augmented reality. Front. Aging Neurosci. 8:80. doi: 10.3389/fnagi.2016.00080

Clark, D. J., Christou, E. A., Ring, S. A., Williamson, J. B., and Doty, L. (2014a). Enhanced somatosensory feedback reduces prefrontal cortical activity during walking in older adults. J. Gerontol. Ser. A Biol. Sci. Med. Sci. 69, 1422-1428. doi: 10.1093/gerona/glu125

Clark, D. J., Rose, D. K., Ring, S. A., and Porges, E. C. (2014b). Utilization of central nervous system resources for preparation and performance of complex walking tasks in older adults. Front. Aging Neurosci. 6:217. doi: 10.3389/fnagi.2014.00217

Dakin, C. J., Son, G. M., Inglis, J. T., and Blouin, J.-S. (2007). Frequency response of human vestibular reflexes characterized by stochastic stimuli. J. Physiol. 583(Pt 3), 1117-1127. doi: 10.1113/jphysiol.2007.133264

Dalton, B. H., Blouin, J. S., Allen, M. D., Rice, C. L., and Inglis, J. T. (2014). The altered vestibular-evoked myogenic and whole-body postural responses in old men during standing. Exp. Gerontol. 60, 120-128. doi: 10.1016/j.exger.2014.09.020

Day, B. L., Steiger, M. J., Thompson, P. D., and Marsden, C. D. (1993). Effect of vision and stance width on human body motion when standing: implications for afferent control of lateral sway. J. Physiol. 469, 479-499. doi: 10.1113/jphysiol.1993.sp019824

de Oliveira, C. B., de Medeiros, I. R., Frota, N. A., Greters, M. E., Conforto, A. B. A., Barros de Oliveira, C., et al. (2008). Balance control in hemiparetic stroke patients: main tools for evaluation. J. Rehabil. Res. Dev. 45, 1215-1226. doi: 10.1682/JRRD.2007.09.0150

De Sanctis, P., Butler, J. S., Malcolm, B. R., and Foxe, J. J. (2014). Recalibration of inhibitory control systems during walking-related dual-task interference: a mobile brain-body imaging (MOBI) study. Neuroimage 94, 55-64. doi: 10.1016/j.neuroimage.2014.03.016

Del Percio, C., Babiloni, C., Marzano, N., Iacoboni, M., Infarinato, F., Vecchio, F., et al. (2009). Neural efficiency of athletes' brain for upright standing: a high-resolution EEG study. Brain Res. Bull. 79, 193-200. doi: 10.1016/j.brainresbull.2009.02.001

Del Percio, C., Brancucci, A., Bergami, F., Marzano, N., Fiore, A., Di Ciolo, E., et al. (2007). Cortical alpha rhythms are correlated with body sway during quiet open-eyes standing in athletes: a high-resolution EEG study. Neuroimage 36, 822-829. doi: 10.1016/j.neuroimage.2007.02.054

Dietz, V., Quintern, J., and Berger, W. (1984). Cerebral evoked potentials associated with the compensatory reactions following stance and gait perturbation. Neurosci. Lett. 50, 181-186. doi: 10.1016/0304-3940(84)90483-X

Dobkin, B. H., Firestine, A., West, M., Saremi, K., and Woods, R. (2004). Ankle dorsiflexion as an fMRI paradigm to assay motor control for walking during rehabilitation. Neuroimage 23, 370-381. doi: 10.1016/j.neuroimage.2004.06.008

Doi, T., Makizako, H., Shimada, H., Park, H., Tsutsumimoto, K., Uemura, K., et al. (2013). Brain activation during dual-task walking and executive function among older adults with mild cognitive impairment: a fNIRS study. Aging Clin. Exp. Res. 25, 539-544. doi: 10.1007/s40520-013-0119-5

Donelan, J. M., Shipman, D. W., Kram, R., and Kuo, A. D. (2004). Mechanical and metabolic requirements for active lateral stabilization in human walking. J. Biomech. 37, 827-835. doi: 10.1016/j.jbiomech.2003.06.002

Dubost, V., Kressig, R. W., Gonthier, R., Herrmann, F. R., Aminian, K., Najafi, B., et al. (2006). Relationships between dual-task related changes in stride velocity and stride time variability in healthy older adults. Hum. Mov. Sci. 25, 372-382. doi: 10.1016/j.humov.2006.03.004

Fitzpatrick, R., Burke, D., and Gandevia, S. C. (1994). Task-dependent reflex responses and movement illusions evoked by galvanic vestibular stimulation in standing humans. J. Physiol. 478 (Pt 2), 363-372. doi: 10.1113/jphysiol.1994.sp020257

Francis, C. A., Franz, J. R., O'Connor, S. M., and Thelen, D. G. (2015). Gait variability in healthy old adults is more affected by a visual perturbation than by a cognitive or narrow step placement demand. Gait Posture 42, 380-385. doi: 10.1016/j.gaitpost.2015.07.006

Franz, J. R., Francis, C. A., Allen, M. S., O’Connor, S. M., and Thelen, D. G. (2015). Advanced age brings a greater reliance on visual feedback to maintain balance during walking. Hum. Mov. Sci. 40, 381-392. doi: 10.1016/j.humov.2015.01.012

Franz, J. R., Francis, C., Allen, M., and Thelen, D. G. (2016). Visuomotor entrainment and the frequency-dependent response of walking balance to perturbations. IEEE Trans. Neural Syst. Rehabil. Eng. 4320:1. doi: 10.1109/TNSRE.2016.2603340

Fujita, H., Kasubuchi, K., Wakata, S., Hiyamizu, M., and Morioka, S. (2016). Role of the frontal cortex in standing postural sway tasks while dual-tasking: a functional near-infrared spectroscopy study examining working memory capacity. Biomed Res. Int. 2016:7053867. doi: 10.1155/2016/7053867

Gauchard, G., Chau, N., Mur, J. M., and Perrin, P. (2001). Falls and working individuals: role of extrinsic and intrinsic factors. Ergonomics 44, 1330-1339. doi: $10.1080 / 00140130110084791$ 
Goodworth, A., Perrone, K., Pillsbury, M., and Yargeau, M. (2015). Effects of visual focus and gait speed on walking balance in the frontal plane. Hum. Mov. Sci. 42, 15-26. doi: 10.1016/j.humov.2015.04.004

Gramann, K., Ferris, D. P., Gwin, J., and Makeig, S. (2014). Imaging natural cognition in action. Int. J. Psychophysiol. 91, 22-29. doi: 10.1016/j.ijpsycho.2013.09.003

Gramann, K., Gwin, J. T., Bigdely-Shamlo, N., Ferris, D. P., and Makeig, S. (2010). Visual evoked responses during standing and walking. Front. Hum. Neurosci. 4:202. doi: 10.3389/fnhum.2010.00202

Gurfinkel, V. S., Lipshits, M. I., Mori, S., and Popov, K. E. (1976). Postural reactions to the controlled sinusoidal displacement of the supporting platform. Agressologie 17, 71-76.

Gwin, J. T., Gramann, K., Makeig, S., and Ferris, D. P. (2011). Electrocortical activity is coupled to gait cycle phase during treadmill walking. Neuroimage 54, 1289-1296. doi: 10.1016/j.neuroimage.2010.08.066

Gwin, J. T., Gramann, K., Makeig, S., and Ferris, D. P. (2010). Removal of movement artifact from high-density EEG recorded during walking and running. J. Neurophysiol. 103, 3526-3534. doi: 10.1152/jn.00105.2010

Haefeli, J., Vöegeli, S., Michel, J., and Dietz, V. (2011). Preparation and performance of obstacle steps: interaction between brain and spinal neuronal activity. Eur. J. Neurosci. 33, 338-348. doi: 10.1111/j.1460-9568.2010. 07494.x

Hamacher, D., Herold, F., Wiegel, P., Hamacher, D., and Schega, L. (2015). Brain activity during walking: a systematic review. Neurosci. Biobehav. Rev. 57, 310-327. doi: 10.1016/j.neubiorev.2015.08.002

Hay, L., Bard, C., Fleury, M., and Teasdale, N. (1996). Availability of visual and proprioceptive afferent messages and postural control in elderly adults. Exp. Brain Res. 108, 129-139. doi: 10.1007/BF00242910

Holtzer, R., Mahoney, J. R., Izzetoglu, M., Izzetoglu, K., Onaral, B., and Verghese, J. (2011). fNIRS study of walking and walking while talking in young and old individuals. J. Gerontol. Ser. A Biol. Sci. Med. Sci. 66, 879-887. doi: 10.1093/gerona/glr068

Holtzer, R., Mahoney, J. R., Izzetoglu, M., Wang, C., England, S., and Verghese, J. (2015). Online fronto-cortical control of simple and attention-demanding locomotion in humans. Neuroimage 112, 152-159. doi: 10.1016/j.neuroimage.2015.03.002

Holtzer, R., Verghese, J., Allali, G., Izzetoglu, M., Wang, C., and Mahoney, J. R. (2016). Neurological gait abnormalities moderate the functional brain signature of the posture first hypothesis. Brain Topogr. 29, 334-343. doi: 10.1007/s10548-015-0465-Z

Huang, C. Y., Zhao, C. G., and Hwang, I. S. (2014). Neural basis of postural focus effect on concurrent postural and motor tasks: Phaselocked electroencephalogram responses. Behav. Brain Res. 274, 95-107. doi: 10.1016/j.bbr.2014.07.054

Hülsdünker, T., Mierau, A., and Strueder, H. K. (2016). Higher balance task demands are associated with an increase in individual alpha peak frequency. Front. Hum. Neurosci. 9:695. doi: 10.3389/fnhum.2015.00695

Hülsdünker, T., Mierau, A., Neeb, C., Kleinoder, H., and Struder, H. K. (2015). Cortical processes associated with continuous balance control as revealed by EEG spectral power. Neurosci. Lett. 592, 1-5. doi: 10.1016/j.neulet.2015.02.049

Huppert, T., Schmidt, B., Beluk, N., Furman, J., and Sparto, P. (2013). Measurement of brain activation during an upright stepping reaction task using functional near-infrared spectroscopy. Hum. Brain Mapp. 34, 2817-2828. doi: $10.1002 / \mathrm{hbm} .22106$

Jacobs, J. V., and Horak, F. B. (2007). Cortical control of postural responses. J. Neural Transm. 114, 1339-1348. doi: 10.1007/s00702-007-0657-0

Jacobs, J., Fujiwara, K., Tomita, H., Furune, N., Kunita, K., and Horak, F. B. (2008). Changes in the activity of the cerebral cortex relate to postural response modification when warned of a perturbation. Clin. Neurophysiol. 119, 1431-1442. doi: 10.1016/j.clinph.2008.02.015

Jaeger, L., Marchal-Crespo, L., Wolf, P., Luft, A. R., Riener, R., Michels, L., et al. (2016). On the modulation of brain activation during simulated weight bearing in supine gait-like stepping. Brain Topogr. 29, 193-205. doi: 10.1007/s10548-015-0441-7

Jeon, Y., Nam, C. S., Kim, Y. J., and Whang, M. C. (2011). Eventrelated (De)synchronization (ERD/ERS) during motor imagery tasks: Implications for brain-computer interfaces. Int. J. Ind. Ergon. 41, 428-436. doi: 10.1016/j.ergon.2011.03.005
Karim, H., Fuhrman, S. I., Sparto, P., Furman, J., and Huppert, T. (2013). Functional brain imaging of multi-sensory vestibular processing during computerized dynamic posturography using near-infrared spectroscopy. Neuroimage 74, 318-325. doi: 10.1016/j.neuroimage.2013.02.010

Kay, B. A., and Warren, W. H. (2001). Coupling of posture and gait: mode locking and parametric excitation. Biol. Cybern. 85, 89-106. doi: 10.1007/PL00008002

Kim, H. Y., Yang, S. P., Park, G. L., Kim, E. J., and You, J. S. H. (2016) Best facilitated cortical activation during different stepping, treadmill, and robot-assisted walking training paradigms and speeds: a functional nearinfrared spectroscopy neuroimaging study. NeuroRehabilitation 38, 171-178. doi: 10.3233/NRE-161307

Kline, J. E., Huang, H. J., Snyder, K. L., and Ferris, D. P. (2015). Isolating gaitrelated movement artifacts in electroencephalography during human walking. J. Neural Eng. 12:46022. doi: 10.1088/1741-2560/12/4/046022

Kline, J. E., Poggensee, K., and Ferris, D. P. (2014). Your brain on speed: cognitive performance of a spatial working memory task is not affected by walking speed. Front. Hum. Neurosci. 8:288. doi: 10.3389/fnhum.2014.00288

Koenraadt, K. L., Roelofsen, E. G., Duysens, J., and Keijsers, N. L. (2014). Cortical control of normal gait and precision stepping: an fNIRS study. Neuroimage 85, 415-422. doi: 10.1016/j.neuroimage.2013.04.070

Kurz, M. J., Wilson, T. W., and Arpin, D. J. (2012). Stride-time variability and sensorimotor cortical activation during walking. Neuroimage 59, 1602-1607. doi: 10.1016/j.neuroimage.2011.08.084

la Fougere, C., Zwergal, A., Rominger, A., Foerster, S., Fesl, G., Dieterich, M., et al. (2010). Real versus imagined locomotion: a [F-18]-FDG PET-fMRI comparison. Neuroimage 50, 1589-1598. doi: 10.1016/j.neuroimage.2009.12.060

Lau, T. M., Gwin, J. T., and Ferris, D. P. (2014). Walking reduces sensorimotor network connectivity compared to standing. J. Neuroeng. Rehabil. 11:14. doi: 10.1186/1743-0003-11-14

Lau, T. M., Gwin, J. T., McDowell, K. G., and Ferris, D. P. (2012). Weighted phase lag index stability as an artifact resistant measure to detect cognitive EEG activity during locomotion. J. Neuroeng. Rehabil. 9:47. doi: 10.1186/1743-0003-9-47

Li, Y., and Nam, C. S. (2016). Collaborative brain-computer interface for people with motor disabilities [Research Frontier]. IEEE Comput. Intell. Magaz. 11, 56-66. doi: 10.1109/MCI.2016.2572558

Liberati, A., Altman, D. G., Tetzlaff, J., Mulrow, C., Gøtzsche, P. C., Ioannidis, J. P. A., et al. (2009). The PRISMA statement for reporting systematic reviews and meta-analyses of studies that evaluate health care interventions: explanation and elaboration. J. Clin. Epidemiol. 62, e1-34. doi: 10.1016/j.jclinepi.2009.06.006

Lin, M.-I. B., and Lin, K.-H. (2016). Walking while performing working memory tasks changes the prefrontal cortex hemodynamic activations and gait kinematics. Front. Behav. Neurosci. 10:9. doi: 10.3339/fnbeh.2010.0009

Little, C. E., and Woollacott, M. (2015). EEG measures reveal dual-task interference in postural performance in young adults. Exp. Brain Res. 233, 27-37. doi: 10.1007/s00221-014-4111-x

Lu, C. F., Liu, Y. C., Yang, Y. R., Wu, Y. T., and Wang, R. Y. (2015). Maintaining gait performance by cortical activation during dual-task interference: a functional near-infrared spectroscopy study. PLoS ONE 10:e0129390. doi: 10.1371/journal.pone.0129390

Luu, T. P., He, Y., Brown, S., Nakagome, S., and Contreras-Vidal, J. L. (2016). Gait adaptation to visual kinematic perturbations using a real-time closed loop brain-computer interface to a virtual reality avatar. J. Neural Eng. 13, 1-13. doi: 10.1109/ICVR.2015.7358598

Maidan, I., Bernad-Elazari, H., Gazit, E., Giladi, N., Hausdorff, J. M., and Mirelman, A. (2015). Changes in oxygenated hemoglobin link freezing of gait to frontal activation in patients with Parkinson disease: an fNIRS study of transient motor-cognitive failures. J. Neurol. 262, 899-908. doi: 10.1007/s00415-015-7650-6

Makeig, S. J., Bell, A., Jung, T.-P., and Sejnowski, T. J. (1996). Independent component analysis of electroencephalographic data. Adv. Neural Inf. Process. Syst. 8, 145-151. doi: 10.1109/ICOSP.2002.1180091

Malcolm, B. R., Foxe, J. J., Butler, J. S., and De Sanctis, P. (2015). The aging brain shows less flexible reallocation of cognitive resources during dual-task walking: a mobile brain/body imaging (MoBI) study. Neuroimage 117, 230-242. doi: 10.1016/j.neuroimage.2015.05.028 
Marlin, A., Mochizuki, G., Staines, W. R., and McIlroy, W. E. (2014). Localizing evoked cortical activity associated with balance reactions: does the anterior cingulate play a role? J. Neurophysiol. 111, 2634-2643. doi: 10.1152/jn.00511.2013

McAndrew, P. M., Wilken, J. M., and Dingwell, J. B. (2011). Dynamic stability of human walking in visually and mechanically destabilizing environments. J. Biomech. 44, 644-649. doi: 10.1016/j.jbiomech.2010.11.007

Mierau, A., Hülsdünker, T., and Strüder, H. K. (2015). Changes in cortical activity associated with adaptive behavior during repeated balance perturbation of unpredictable timing. Front. Behav. Neurosci. 9:272. doi: 10.3389/fnbeh.2015.00272

Mihara, M., Miyai, I., Hatakenaka, M., Kubota, K., and Sakoda, S. (2007). Sustained prefrontal activation during ataxic gait: a compensatory mechanism for ataxic stroke? Neuroimage 37, 1338-1345. doi: 10.1016/j.neuroimage.2007.06.014

Mihara, M., Miyai, I., Hatakenaka, M., Kubota, K., and Sakoda, S. (2008). Role of the prefrontal cortex in human balance control. Neuroimage 43, 329-336. doi: 10.1016/j.neuroimage.2008.07.029

Mihara, M., Miyai, I., Hattori, N., Hatakenaka, M., Yagura, H., Kawano, T., et al. (2012). Cortical control of postural balance in patients with hemiplegic stroke. Neuroreport 23, 314-319. doi: 10.1097/WNR.0b013e328351757b

Mirelman, A., Maidan, I., Bernad-Elazari, H., Nieuwhof, F., Reelick, M., Giladi, N., et al. (2014). Increased frontal brain activation during walking while dual tasking: an fNIRS study in healthy young adults. J. Neuroeng. Rehabil. 11:85. doi: 10.1186/1743-0003-11-85

Mitsutake, T., Sakamoto, M., and Horikawa, E. (2015). Effect of neck and trunk rotation speeds on cerebral cortex activity and standing postural stability: a functional near-infrared spectroscopy study. J. Phys. Ther. Sci. 27, 2817-2819. doi: $10.1589 /$ jpts.27.2817

Miyai, I., Tanabe, H. C., Sase, I., Eda, H., Oda, I., Konishi, I., et al. (2001). Cortical mapping of gait in humans: a near-infrared spectroscopic topography study. Neuroimage 14, 1186-1192. doi: 10.1006/nimg.2001.0905

Mochizuki, G., Sibley, K. M., Cheung, H. J., Camilleri, J. M., and McIlroy, W. E. (2009a). Generalizability of perturbation-evoked cortical potentials: independence from sensory, motor and overall postural state. Neurosci. Lett. 451, 40-44. doi: 10.1016/j.neulet.2008.12.020

Mochizuki, G., Sibley, K. M., Cheung, H. J., and McIlroy, W. E. (2009b). Cortical activity prior to predictable postural instability: Is there a difference between self-initiated and externally-initiated perturbations? Brain Res. 1279, 29-36. doi: 10.1016/j.brainres.2009.04.050

Mochizuki, G., Sibley, K. M., Esposito, J. G., Camilleri, J. M., and McIlroy, W. E. (2008). Cortical responses associated with the preparation and reaction to full-body perturbations to upright stability. Clin. Neurophysiol. 119, 1626-1637. doi: 10.1016/j.clinph.2008.03.020

Mullie, Y., and Duclos, C. (2014). Role of proprioceptive information to control balance during gait in healthy and hemiparetic individuals. Gait Posture 40, 610-615. doi: 10.1016/j.gaitpost.2014.07.008

Nagai, Y., Critchley, H. D., Featherstone, E., Fenwick, P. B., Trimble, M. R., and Dolan, R. J. (2004). Brain activity relating to the contingent negative variation: an fMRI investigation. Neuroimage 21, 1232-1241. doi: 10.1016/j.neuroimage.2003.10.036

Nam, C. S., Jeon, Y., Kim, Y. J., Lee, I., and Park, K. (2011). Movement imageryrelated lateralization of event-related (de)synchronization (ERD/ERS): motor-imagery duration effects. Clin. Neurophysiol. 122, 567-577. doi: 10.1016/j.clinph.2010.08.002

Nam, C. S., Woo, J., and Bahn, S. (2012). Severe motor disability affects functional cortical integration in the context of brain-computer interface (BCI) use. Ergonomics 55, 581-591. doi: 10.1080/00140139.2011.647095

Nathan, K., and Contreras-Vidal, J. L. (2016). Negligible motion artifacts in scalp Electroencephalography (EEG) during treadmill walking. Front. Hum. Neurosci. 9:708. doi: 10.3389/fnhum.2015.00708

O'Connor, S. M., and Kuo, A. D. (2009). Direction-dependent control of balance during walking and standing. J. Neurophysiol. 102, 1411-1419. doi: 10.1152/jn.00131.2009

O'Connor, S. M., Xu, H. Z., and Kuo, A. D. (2012). Energetic cost of walking with increased step variability. Gait Posture 36, 102-107. doi: 10.1016/j.gaitpost.2012.01.014

Oliveira, A., Schlink, B., Hairston, W. D., König, P., and Ferris, D. P. (2016). Proposing metrics for benchmarking novel EEG technologies towards real-world measurements. Front. Hum. Neurosci. 10:188 doi: 10.3389/fnhum.2016.00188

Osofundiya, O., Benden, M. E., Dowdy, D., and Mehta, R. K. (2016). Obesity-specific neural cost of maintaining gait performance under complex conditions in community-dwelling older adults. Clin. Biomech. 35, 42-48. doi: 10.1016/j.clinbiomech.2016.03.011

Ouchi, Y., Okada, H., Yoshikawa, E., Nobezawa, S., and Futatsubashi, M. (1999). Brain activation during maintenance of standing postures in humans. Brain 122, 329-338. doi: 10.1093/brain/122.2.329

Petersen, T. H., Willerslev-Olsen, M., Conway, B. A., and Nielsen, J. B. (2012). The motor cortex drives the muscles during walking in human subjects. J. Physiol. 590, 2443-2452. doi: 10.1113/jphysiol.2012.227397

Petrofsky, J. S., and Khowailed, I. A. (2014). Postural sway and motor control in trans-tibial amputees as assessed by electroencephalography during eight balance training tasks. Med. Sci. Monit. 20, 2695-2704. doi: 10.12659/MSM.891361

Pirini, M., Mancini, M., Farella, E., and Chiari, L. (2011). EEG correlates of postural audio-biofeedback. Hum. Mov. Sci. 30, 249-261. doi: 10.1016/j.humov.2010.05.016

Plummer, P., Apple, S., Dowd, C., and Keith, E. (2015). Texting and walking: effect of environmental setting and task prioritization on dual-task interference in healthy young adults. Gait Posture 41, 46-51. doi: 10.1016/j.gaitpost.2014.08.007

Presacco, A., Forrester, L. W., and Contreras-Vidal, J. L. (2012). Decoding intra-limb and inter-limb kinematics during treadmill walking from scalp electroencephalographic (EEG) signals. IEEE Trans. Neural Syst. Rehabil. Eng. 20, 212-219. doi: 10.1109/TNSRE.2012.2188304

Presacco, A., Goodman, R., Forrester, L., and Contreras-Vidal, J. L. (2011). Neural decoding of treadmill walking from noninvasive electroencephalographic signals. J. Neurophysiol. 106, 1875-1887. doi: 10.1152/jn.00104.2011

Priest, A. W., Salamon, K. B., and Hollman, J. H. (2008). Age-related differences in dual task walking: a cross sectional study. J. Neuroeng. Rehabil. 5:29. doi: 10.1186/1743-0003-5-29

Quant, S., Adkin, A. L., Staines, W. R., Maki, B. E., and Mcllroy, W. E. (2004). The effect of a concurrent cognitive task on cortical potentials evoked by unpredictable balance perturbations. BMC Neurosci. 5:18. doi: 10.1186/1471-2202-5-18

Quant, S., Maki, B., and Mcllroy, W. E. (2005). The association between later cortical potentials and later phases of postural reactions evoked by perturbations to upright stance. Neurosci. Lett. 381, 269-274. doi: 10.1016/j.neulet.2005.02.015

Rankin, B. L., Buffo, S. K., and Dean, J. C. (2014). A neuromechanical strategy for mediolateral foot placement in walking humans. J. Neurophysiol. 112, 374-383. doi: 10.1152/jn.00138.2014

Sheehan, R. C., Beltran, E. J., Dingwell, J. B., and Wilken, J. M. (2015). Mediolateral angular momentum changes in persons with amputation during perturbed walking. Gait Posture 41, 795-800. doi: 10.1016/j.gaitpost.2015.02.008

Shimada, H., Ishii, K., Ishiwata, K., Oda, K., Suzukawa, M., Makizako, H., et al. (2013). Gait adaptability and brain activity during unaccustomed treadmill walking in healthy elderly females. Gait Posture 38, 203-208. doi: 10.1016/j.gaitpost.2012.11.008

Shine, J. M., Matar, E., Ward, P. B., Bolitho, S. J., Pearson, M., Naismith, S. L., et al. (2013a). Differential neural activation patterns in patients with Parkinson's disease and freezing of gait in response to concurrent cognitive and motor load. PLoS ONE 8:e52602. doi: 10.1371/journal.pone.0052602

Shine, J. M., Matar, E., Ward, P. B., Frank, M. J., Moustafa, A. A., Pearson, M., et al. (2013b). Freezing of gait in Parkinson's disease is associated with functional decoupling between the cognitive control network and the basal ganglia. Brain 136, 3671-3681. doi: 10.1093/brain/awt272

Sinitksi, E. H., Terry, K., Wilken, J. M., and Dingwell, J. B. (2012). Effects of perturbation magnitude on dynamic stability when walking in destabilizing environments. J. Biomech. 45, 2084-2091. doi: 10.1016/j.jbiomech.2012.05.039

Sipp, A. R., Gwin, J. T., Makeig, S., and Ferris, D. P. (2013). Loss of balance during balance beam walking elicits a multifocal theta band electrocortical response. J. Neurophysiol. 110, 2050-2060. doi: 10.1152/jn.00744.2012

Slobounov, S., Cao, C., Jaiswal, N., and Newell, K. M. (2009). Neural basis of postural instability identified by VTC and EEG. Exp. Brain Res. 199, 1-16. doi: 10.1007/s00221-009-1956-5 
Slobounov, S., Hallett, M., Cao, C., and Newell, K. (2008). Modulation of cortical activity as a result of voluntary postural sway direction: an EEG study. Neurosci. Lett. 442, 309-313. doi: 10.1016/j.neulet.2008.07.021

Slobounov, S., Hallett, M., Stanhope, S., and Shibasaki, H. (2005). Role of cerebral cortex in human postural control: an EEG study. Clin. Neurophysiol. 116, 315-323. doi: 10.1016/j.clinph.2004.09.007

Slobounov, S., Ray, W., Johnson, B., Slobounov, E., and Newell, K. M. (2015). Modulation of cortical activity in 2D versus 3D virtual reality environments: an EEG study. Int. J. Psychophysiol. 95, 254-260. doi: 10.1016/j.ijpsycho.2014.11.003

Slobounov, S., Teel, E., and Newell, K. M. (2013). Modulation of cortical activity in response to visually induced postural perturbation: combined VR and EEG study. Neurosci. Lett. 547, 6-9. doi: 10.1016/j.neulet.2013.05.001

Smith, B. A., Jacobs, J. V., and Horak, F. B. (2012). Effects of magnitude and magnitude predictability of postural perturbations on preparatory cortical activity in older adults with and without Parkinson's disease. Exp. Brain Res. 222, 455-470. doi: 10.1007/s00221-012-3232-3

Smith, B. A., Jacobs, J. V., and Horak, F. B. (2014). Effects of amplitude cueing on postural responses and preparatory cortical activity of people with Parkinson disease. J. Neurol. Phys. Ther. 38, 207-215. doi: 10.1097/NPT.0000000000000058

Snyder, K. L., Kline, J. E., Huang, H. J., and Ferris, D. P. (2015). Independent component analysis of gait-related movement artifact recorded using EEG electrodes during treadmill walking. Front. Hum. Neurosci. 9:639. doi: 10.3389/fnhum.2015.00639

Storzer, L., Butz, M., Hirschmann, J., Abbasi, O., Gratkowski, M., Saupe, D., et al. (2016). Bicycling and walking are associated with different cortical oscillatory dynamics. Front. Hum. Neurosci. 10:61. doi: 10.3389/fnhum.2016.00061

Suzuki, M., Miyai, I., Ono, T., Oda, I., Konishi, I., Kochiyama, T., et al. (2004). Prefrontal and premotor cortices are involved in adapting walking and running speed on the treadmill: an optical imaging study. Neuroimage 23, 1020-1026. doi: 10.1016/j.neuroimage.2004.07.002

Takeuchi, N., Mori, T., Suzukamo, Y., Tanaka, N., and Izumi, S.-I. (2016). Parallel processing of cognitive and physical demands in left and right prefrontal cortices during smartphone use while walking. BMC Neurosci. 17:9. doi: $10.1186 /$ s12868-016-0244-0
Tse, Y. Y. F., Petrofsky, J. S., Berk, L., Daher, N., Lohman, E., Laymon, M. S., et al. (2013). Postural sway and rhythmic electroencephalography analysis of cortical activation during eight balance training tasks. Med. Sci. Monit. 19, 175-186. doi: 10.12659/MSM.883824

Varghese, J., Beyer, K. B., Williams, L., Miyasike-daSilva, V., and McIlroy, W. E. (2015). Standing still: is there a role for the cortex? Neurosci. Lett. 590, 18-23. doi: 10.1016/j.neulet.2015.01.055

Varghese, J. P., Marlin, A., Beyer, K. B., Staines, W. R., Mochizuki, G., and Mcllroy, W. E. (2014). Frequency characteristics of cortical activity associated with perturbations to upright stability. Neurosci. Lett. 578, 33-38. doi: 10.1016/j.neulet.2014.06.017

Varghese, J., Merino, D. M., Beyer, K. B., and Mcilroy, W. E. (2016). Cortical control of anticipatory postural adjustments prior to stepping. Neuroscience 313, 99-109. doi: 10.1016/j.neuroscience.2015. 11.032

Wajda, D. A., and Sosnoff, J. J. (2015). Cognitive-motor interference in multiple sclerosis: a systematic review of evidence, correlates, and consequences. Biomed Res. Int. 2015:720856. doi: 10.1155/2015/720856

Wallois, F., Mahmoudzadeh, M., Patil, A., and Grebe, R. (2012). Usefulness of simultaneous EEG-NIRS recording in language studies. Brain Lang. 121, 110-123. doi: 10.1016/j.bandl.2011.03.010

Zwergal, A., la Fougère, C., Lorenzl, S., Rominger, A., Xiong, G., Deutschenbaur, L., et al. (2013). Functional disturbance of the locomotor network in progressive supranuclear palsy. Neurology 80, 634-641. doi: 10.1212/WNL.0b013e318281cc43

Conflict of Interest Statement: The authors declare that the research was conducted in the absence of any commercial or financial relationships that could be construed as a potential conflict of interest.

Copyright (c) 2017 Wittenberg, Thompson, Nam and Franz. This is an open-access article distributed under the terms of the Creative Commons Attribution License (CC $B Y)$. The use, distribution or reproduction in other forums is permitted, provided the original author(s) or licensor are credited and that the original publication in this journal is cited, in accordance with accepted academic practice. No use, distribution or reproduction is permitted which does not comply with these terms. 